\title{
Quantitative Rodent Brain Receptor Imaging
}

\author{
Kristina Herfert $\odot,{ }^{1}$ Julia G. Mannheim, ${ }^{1}$ Laura Kuebler, ${ }^{1}$ Sabina Marciano, ${ }^{1}$ \\ Mario Amend, ${ }^{1}$ Christoph Parl, ${ }^{1}$ Hanna Napieczynska, ${ }^{1}$ Florian M. Maier, ${ }^{1}$ \\ Salvador Castaneda Vega, ${ }^{1,2}$ Bernd J. Pichler ${ }^{1}$ \\ ${ }^{1}$ Werner Siemens Imaging Center, Department of Preclinical Imaging and Radiopharmacy, University of Tuebingen, Tuebingen, Germany \\ ${ }^{2}$ Department of Nuclear Medicine and Clinical Molecular Imaging, University of Tuebingen, Tuebingen, Germany
}

\begin{abstract}
Positron emission tomography (PET) is a non-invasive imaging technology employed to describe metabolic, physiological, and biochemical processes in vivo. These include receptor availability, metabolic changes, neurotransmitter release, and alterations of gene expression in the brain. Since the introduction of dedicated small-animal PET systems along with the development of many novel PET imaging probes, the number of PET studies using rats and mice in basic biomedical research tremendously increased over the last decade. This article reviews challenges and advances of quantitative rodent brain imaging to make the readers aware of its physical limitations, as well as to inspire them for its potential applications in preclinical research. In the first section, we briefly discuss the limitations of small-animal PET systems in terms of spatial resolution and sensitivity and point to possible improvements in detector development. In addition, different acquisition and post-processing methods used in rodent PET studies are summarized. We further discuss factors influencing the test-retest variability in small-animal PET studies, e.g., different receptor quantification methodologies which have been mainly translated from human to rodent receptor studies to determine the binding potential and changes of receptor availability and radioligand affinity. We further review different kinetic modeling approaches to obtain quantitative binding data in rodents and PET studies focusing on the quantification of endogenous neurotransmitter release using pharmacological interventions. While several studies have focused on the dopamine system due to the availability of several PET tracers which are sensitive to dopamine release, other neurotransmitter systems have become more and more into focus and are described in this review, as well. We further provide an overview of latest genome engineering technologies, including the CRISPR/Cas9 and DREADD systems that may advance our understanding of brain disorders and function and how imaging has been successfully applied to animal models of human brain disorders. Finally, we review the strengths and opportunities of simultaneous PET/magnetic resonance imaging systems to study drug-receptor interactions and challenges for the translation of PET results from bench to bedside.
\end{abstract}

Key words: Rats, Mice, Brain, PET imaging, Receptor quantification

Correspondence to: Kristina Herfert; e-mail: kristina.herfert@med.unituebingen.de

\section{Introduction}

The demographic change has led to a continuously increasing number of aging people around the world who suffer from neurodegenerative or neuropsychiatric diseases such as 
Parkinson's disease (PD), Alzheimer's disease (AD), major depression, and anxiety. Therefore, research on those disorders with regard to diagnosis, staging, and the development of novel therapies is of great medical and sociopolitical importance.

Due to ethical considerations and legal requirements, many research questions - including some questions relevant to the development of novel therapies, drugs, and biomarkers - cannot be directly addressed in humans. Therefore, disease models using animals, e.g., mice, rats, and non-human primates, are indispensable for biomedical research. In particular, transgenic mouse and rat models of neurological disorders have greatly advanced our understanding of many brain disorders and may provide new avenues to therapy development [1-6].

Non-invasive imaging bridges the gaps between basic, preclinical, and clinical science and, furthermore, links interdisciplinary approaches and methods from pharmacology, physics, chemistry, physiology, and genetics to gain complementary information about the tissue of interest. The technical progress of dedicated small-animal positron emission tomography (PET) systems along with the development of novel radiotracers has led to the use of PET in small laboratory animal models in basic, preclinical, and translational settings. The main advantage of small-animal PET in preclinical and fundamental science is that studies can be performed in vivo using longitudinal study designs in the same animals, minimizing the number of animals needed per cohort and maximizing the statistical utility of the data, since the same animals can be measured at several time points; by contrast, immunohistochemical or other hybridization experiments require animals to be sacrificed at each measurement time point. Small-animal PET led to advancements in the fundamental understanding of molecular mechanisms of diseases in basic research, resulting in the development of therapies and new disease models in the preclinical field; however, the successful translation of these advancements to the clinical field has often proven to be difficult. This is partially related to interspecies differences in genetics and physiology between humans and rodents [7]. However, it also involves a qualitative and quantitative issue related to a superficial description of methods and models used in a certain study leading to results which are not reproducible. Furthermore, inaccurate study designs as well as incorrect data analysis and interpretation will largely impact outcome parameters.

In addition, small-animal PET technology has inherent physical limitations that can affect the accuracy of quantification $[8,9]$. Moreover, the limited time resolution of these systems makes the detection of fast molecular and functional changes in dynamic processes difficult. In addition, the pharmacokinetics of a PET tracer can be described only by very simplified models and methods, which insufficiently account the complex biology. The inaccuracies and deficits of quantification must be taken into account for data analysis and interpretation. This includes the estimation of binding values from bolus injection experiments, the mass effect, and the partial-volume effect (PVE). In addition, animal handling, data acquisition, reconstruction, and corrections must be carefully evaluated and standardized before PET experiments can be performed in a quantitative manner (Fig. 1). This review aims to give an overview of the challenges, opportunities, and restrictions in rodent brain receptor PET imaging to provide the reader with a clear understanding of its limitations, as well as its unique benefits and strengths in the field of small-animal brain imaging.

\section{Dedicated High-Resolution Small- Animal PET Systems}

Numerous small-animal receptor studies have been performed using commercially available preclinical PET systems [10-16]. However, resolving small structures within rodent brains using PET imaging is feasible but nevertheless challenging due to the relatively low spatial resolution of small-animal PET systems compared to the tiny size of structures in rodent brains. In contrast to human PET scanners, which have a spatial resolution of approximately 4-8 $\mathrm{mm}$ (corresponding to a volumetric resolution of $\sim 64$ $512 \mathrm{~mm}^{3}$ ) [17, 18], currently available small-animal PET systems achieve spatial resolutions in a range of $1.3-1.5 \mathrm{~mm}$ full width at half maximum (FWHM) (corresponding to a volumetric resolution of $\sim 2.2-3.4 \mathrm{~mm}^{3}$ ) in the center of the field of view (FOV) $[19,20]$. The spatial resolution is directly linked to the crystal size, with smaller crystals providing improved spatial resolution, which, due to the parallax effect, usually degrades outside the center of the FOV if long crystals are used [19]. However, shorter crystals decrease the detection sensitivity of the PET system [21]. Therefore, the choice of the detector crystal geometry is always a trade-off. However, most importantly in order to achieve quantifiable results, the systems need to provide reliable and reproducible data in order to enable receptor quantification in small animals. A comparison of currently commercially available small-animal PET scanners can be found in the literature $[19,22]$.

While the human brain has a volume of approximately $1200 \mathrm{~cm}^{3}$, the rat and mouse brains measure $\sim 2$ and $\sim 0.5 \mathrm{~cm}^{3}$, respectively, which makes them approximately 600- and 2400fold smaller than the human brain (Fig. 2). In contrast, the volumetric resolution of preclinical scanners is increased only by a factor of about 30 compared to that of human scanners. Downscaling from the whole brain to particular brain regions, the resulting volumes of interest (VOIs) measure only a few cubic millimeters. Especially in mice, small brain structures with volumes below the volumetric spatial resolution such as the substantia nigra $\left(\sim 2 \mathrm{~mm}^{3}\right)$, the globus pallidus $\left(\sim 2-3 \mathrm{~mm}^{3}\right)$, the nucleus accumbens $\left(\sim 5-6 \mathrm{~mm}^{3}\right)$, the prefrontal $\left(\sim 1.8 \mathrm{~mm}^{3}\right)$ and somatosensory cortex $\left(\sim 6 \mathrm{~mm}^{3}\right)$, the hypothalamus $\left(\sim 6 \mathrm{~mm}^{3}\right)$, and the dorsal $\left(\sim 7-8 \mathrm{~mm}^{3}\right)$ and ventral hippocampus $\left(\sim 6 \mathrm{~mm}^{3}\right)$ [23-25], which are of particular interest with regard to receptor quantification, cannot be fully distinguished from surrounding 


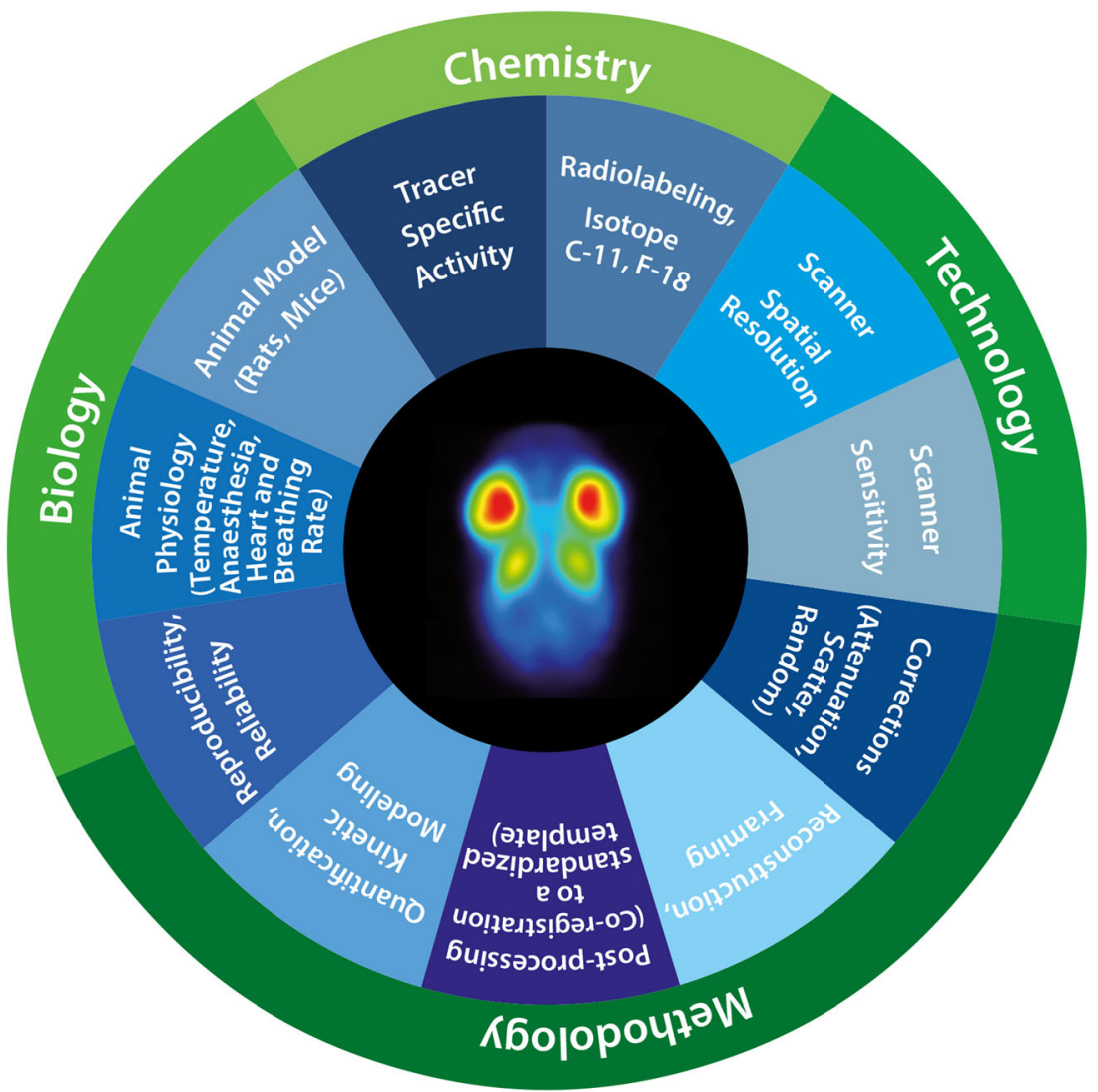

Fig. 1. Technical, methodological, biological, and radiochemical aspects influencing the quantification accuracy of PET brain studies in rodents.

regions. Thus, for a reliable quantification of small brain structures, imaging technologies used to quantify receptor availability changes in the mouse brain need to offer increased spatial resolution, which, in the case of PET, usually results in a loss of sensitivity. However, low sensitivity is a serious issue, especially in small-animal PET studies. Indeed, only a small fraction of the injected tracer accumulates in the rodent brain, and the portion of specifically bound radiotracer (SB) is derived mostly from the ratio of the tracer uptake in a target brain region to the uptake in a reference region over a time period of 30 to $60 \mathrm{~min}$ after injection, when a large proportion of the initial radiotracer dose (usually C-11 tracers with a half-life of $\sim 20 \mathrm{~min}$ ) has already decayed. Increasing the injected dose, however, would lead to a violation of the tracer principle $(<1 \%$ receptor occupancy), leading to a wrong quantification [26].

Thus, to offer quantitatively correct imaging data of rodent receptor functions, small-animal PET systems require both high sensitivity and high spatial resolution. To solve the trade-off between sensitivity and resolution and to improve current PET technology, an ongoing field of research focuses on the optimization of several aspects of the hardware. By taking the fundamental restrictions into account [27], the spatial resolution of a PET system can be optimized by decreasing the ring diameter of the system to the size of a rodent's head. Furthermore, resolving the exact position of the $\gamma$-photons within the crystals allows an

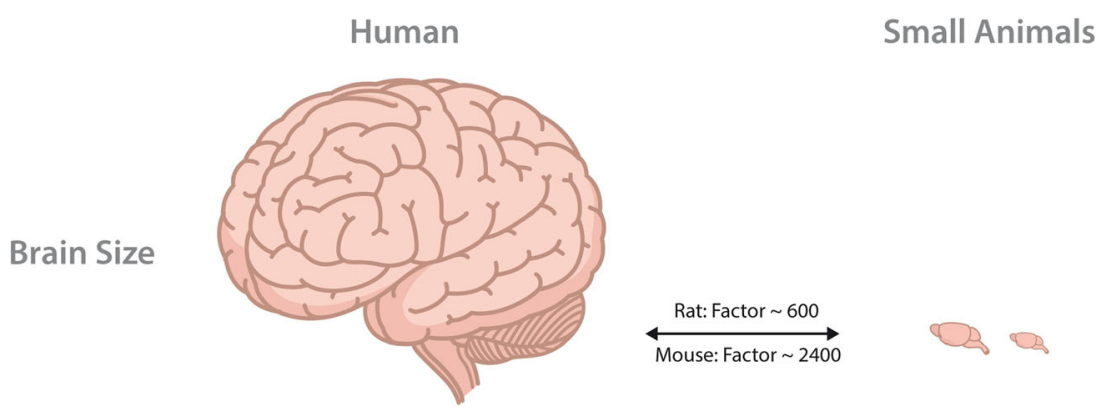

Fig. 2. Comparison between the brain sizes of humans and rodents. 
increased sampling rate within the FOV. This improvement leads to an increase in spatial resolution and helps to keep it constant over the entire FOV [28]. Thus, the depth-ofinteraction resolution addresses the parallax error and enables the use of long crystals in a high-resolution PET system, which increases the sensitivity [28].

Additionally, the FOV of the PET system should be easily accessible, e.g., for providing anesthesia and injecting a tracer or pharmacological substance during the measurement without moving the animal bed or necessitating a long catheter. In particular, the combination of stimulation techniques, such as optogenetic light stimulation or forepaw stimulation, with PET requires space and access to the animal during the measurement.

Furthermore, the combination of high-resolution, highsensitivity small-animal PET systems and high-field magnetic resonance imaging (MRI) technology can provide anatomical and functional data from MRI and molecular information from PET and MRI with high spatial and temporal resolution. This is a unique advantage, since functional information from MRI can be correlated with molecular receptor availability changes detected by PET. Several dedicated high-resolution PET/MRI systems have been developed [29-37].

Detector development is an active ongoing field of research and, undoubtedly, will further improve the resolution and sensitivity of preclinical PET systems in years to come.

\section{Data Acquisition, Corrections, and Reconstruction}

Rodent receptor imaging requires dedicated hardware and software, as well as proper physiological monitoring of the animals, to enable a reliable and quantitatively accurate measurement of receptor availability [8, 38, 39]. PET in general has limited spatial resolution and, depending on the setup, can be subject to relatively high noise levels, especially in dynamic acquisitions of small structures using short half-life tracers [40]. Therefore, the reliability and reproducibility of the acquired data are strongly dependent on standardization of the data acquisition, correction, and reconstruction.

To determine receptor availability using kinetic modeling, dynamic in vivo PET experiments are often conducted. The majority of the PET tracers used for receptor imaging are radiolabeled with the isotope C-11 [41], which enables a simpler labeling process than other isotopes due to the substitution of a methyl group on the tracer molecule with the radioactive isotope $\mathrm{C}-11$. However, more and more F18-labeled radiotracers have been developed over the last years to circumvent specific disadvantages of $\mathrm{C}-11$. These include a short half-life of 20.4 versus $110 \mathrm{~min}$ for F-18 and hence the necessity of an on-site production of high molar activities to avoid mass effects from the injection of large volumes as well as a lower spatial resolution due to the larger positron range of C-11. In addition, with one F-18 synthesis, a larger number of animals can be scanned, reducing synthesis time and costs. Depending on the tracer kinetics, dynamic acquisitions are usually performed over the course of $60-90 \mathrm{~min}$. The temporal resolution of the time-activity curve (TAC) is an important factor for kinetic modeling and is strongly affected by the chosen dynamic framing of the PET acquisition. Shorter frames are desired at the beginning of the acquisition to fully resolve the perfusion peak and fast tracer kinetics, while longer frames are needed at the end of the acquisition to account for the lower count statistics due to the decay of the isotope. Hence, the scanner needs to be able to deal with a relatively large dynamic range of radioactivity and count rate which in turn requires a high detection sensitivity and count rate performance.

Tracer injection can be performed either by bolus injection or by a combination of bolus injection and continuous tracer infusion. Combined bolus infusion protocols are conducted to ensure a continuous equilibrium, in which the tracer is infused at the same rate as it is cleared from the tissue without specific binding sites [42]. By performing such experiments, one can simply derive specific binding from the ratio of the target and reference regions without kinetic modeling, reducing the dependency on a kinetic model [43]. In addition, bolus infusion protocols enable researchers to perform interventional studies within one animal and one single PET experiment. The specific binding at equilibrium represents the baseline condition and can be compared to the specific binding after an intervention (i.e., a drug application). Thus, using such a protocol baseline and intervention can be performed in the same animal and scan which leads to more reliable results and largely reduces the number of animals needed in a study.

The acquired and histogrammed PET data are reconstructed into 3D imaging stacks using analytical or iterative reconstruction methods. While analytical methods, such as the common filtered backprojection (FBP) algorithm, are fast and straightforward to implement, the iterative reconstruction algorithms, e.g., ordered subset expectation maximization (OSEM) algorithm, can include corrections (scanner geometry, etc.), as well as model the statistical noise [40]. As shown in Fig. 3a, different reconstruction algorithms lead to very different outcome measures (Table 1).

Multiple studies have focused on the evaluation of reconstruction parameters for different applications [40, 45-48]. However, up to now, there is, at least to our knowledge, no gold standard reconstruction algorithm available for brain receptor imaging and quantification.

Regardless of the reconstruction method, several physical limitations hamper the quantification accuracy of the acquired data and several basic corrections need to be applied to ensure good reliability and quantification of the data $[49,50]$. A normalization of the system to correct for PET detector inefficiencies shall be applied, along with decay, dead-time, and random corrections. In addition, the quantity of attenuated 


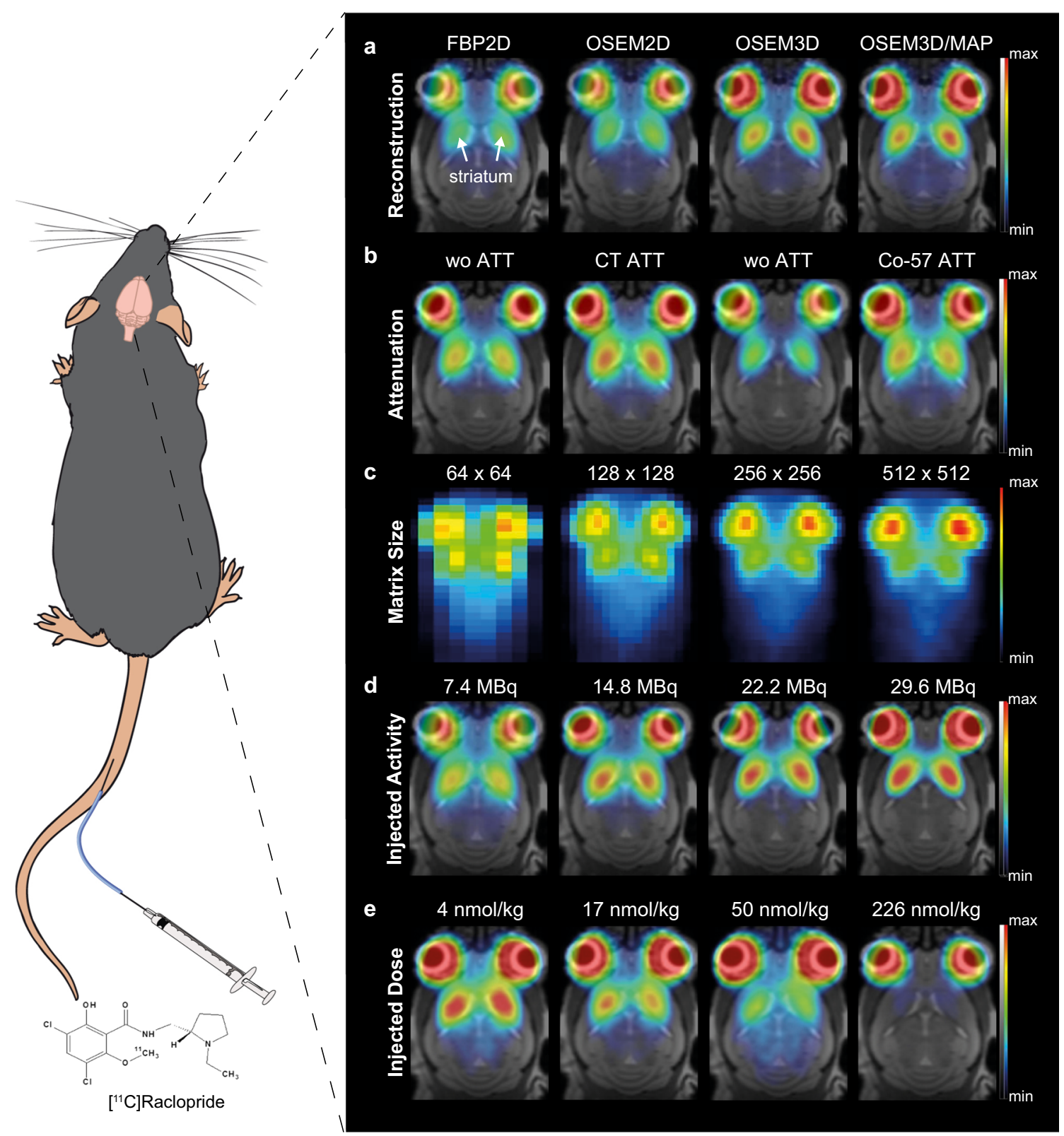

Fig. 3. Comparison of $\left[{ }^{11} \mathrm{C}\right]$ raclopride mouse brain PET images after using different $2 \mathrm{D}$ and $3 \mathrm{D}$ reconstruction algorithms (a), CT versus Co-57 attenuation correction (b), increasing matrix sizes (c), increasing injected activity (d), and increasing injected doses (e). In a, b, c, and e, scans were performed in the same mouse, but in $\mathbf{b}$, two separate scans were performed for the first two (wo ATT and CT ATT) and last two (wo ATT and Co-57 ATT) columns. Different mice of the same strain and age were used in d. Abbreviations: FBP = filtered backprojection, OSEM = ordered subset expectation maximization, MAP = maximum a posteriori, ATT = attenuation, wo ATT = without attenuation correction.

and/or scattered photons should be determined and corrected for by using either an attached CT scanner or an external source to acquire the attenuation data (Fig. 3b and Table 1) [49, 51-54]. This is especially important in small-animal studies, since most of the animal beds are relatively thick due to the integrated heating system. Furthermore, motion correction of the PET data has been studied extensively over the last few decades, and several approaches are available [55-59]. However, to our knowledge, this is currently not implemented on a routine basis for preclinical scanners and remains an important research topic.
In most preclinical PET brain studies, anatomical reference images are not available and PET data are coregistrated to a common MRI brain template [24, 60-62]. This is however a challenging and error-prone process, since many PET tracers do not show uptake in major brain regions, such as cortex, cerebellum, and midbrain, and therefore tracer-specific anatomical reference points are often missing.

One important advancement in data post-processing is the availability of tracer-specific standard brain templates, 
Table 1. $\left[{ }^{11} \mathrm{C}\right]$ Raclopride quantitative values derived from images shown in Fig. 3

\begin{tabular}{|c|c|c|c|c|}
\hline Reconstruction & FBP2D & OSEM2D & OSEM3D & OSEM3D/MAP \\
\hline BPND (SRTM, striatum) & 1.7 & 1.7 & 2.0 & 2.5 \\
\hline Attenuation & wo ATT & CT ATT & wo ATT & Co-57 ATT \\
\hline striatum $[\mathrm{kBq} / \mathrm{cm} 3]$ & 252 & 275 & 189 & 228 \\
\hline cerebellum $[\mathrm{kBq} / \mathrm{cm} 3]$ & 83 & 91 & 81 & 106 \\
\hline BPND (SRTM, striatum) & 1.2 & 1.2 & 0.9 & 1.1 \\
\hline Matrix size & $64 \times 64$ & $128 \times 128$ & $256 \times 256$ & $512 \times 512$ \\
\hline BPND (SRTM, striatum) & 1.4 & 1.6 & 1.8 & 1.6 \\
\hline Injected Activity $[\mathrm{MBq}]$ & 7.4 & 14.8 & 22.2 & 29.6 \\
\hline BPND (SRTM, striatum) & 1.7 & 1.8 & 1.8 & 1.2 \\
\hline Injected Dose $[\mathrm{nmol} / \mathrm{kg}]$ & 4 & 17 & 50 & 226 \\
\hline BPND (SRTM, striatum) & 1.8 & 1.5 & 0.7 & 0.3 \\
\hline
\end{tabular}

The binding potential $\left(\mathrm{BP}_{\mathrm{ND}}\right.$ ) was calculated using the simplified reference tissue model (SRTM) [44] with the cerebellum as the reference tissue

aligned to a standard reference space for several PET radioligands $[63,64]$. This enables the use of an automatic normalization and the application of predefined VOIs, minimizing the user-dependent variability. This is particularly important in small-animal PET brain studies, if a voxelbased analysis is performed and small deviations from the standard space will largely impact the results.

\section{Quantification Accuracy: Partial- Volume Effect, Spillover, Mass Effect, and Data Reproducibility}

In addition to the abovementioned points, the PVE needs to be taken into account when accurate quantitative data are desired. The PVE occurs due to the finite spatial resolution of the PET system and to the activity spillover from the surrounding tissue by either spill-in or spill-out to the target region. As a consequence of the PVE, the measured activity concentration does not reflect the real activity concentration in a given tissue [65-67], altering the PET signal and hence the quantification accuracy [66]. Figure $3 c$ and Table 1 illustrate this effect, which is also referred to as the tissue fraction effect, by comparing different matrix sizes for an $\left[{ }^{11} \mathrm{C}\right]$ raclopride mouse brain PET scan. The resulting voxel value is a combination of different tissue activity levels within the voxel. If a small matrix size is used, different tissue activity levels will contribute to the PET signal within one voxel. However, if the voxel size is too small, the activity concentration within one voxel is very small, resulting in high noise levels that may affect the quantification accuracy. The matrix and corresponding voxel size will consequently have an impact on the PVE and a trade-off has to be accomplished between smaller voxel sizes with less spill-in and spill-out of activity of surrounding tissues compared to higher noise statistics within smaller voxels. The magnitude of the PVE in general is dependent on many individual factors, such as the positron range of the selected isotope, the size of the target, the contrast ratio of the target to the background region, the reconstruction and correction algorithms and parameters, the position of the voxel within the FOV, and the count rate of the acquisition $[54,68,69]$.
In small-animal PET scanners, in which the length ratio of the axial FOV to the transaxial FOV is greater, the PVE seems to be much more distinct than in clinical PET scanners $[54,68]$.

Over the past few years, multiple methods have been developed to correct for the PVE, most of them based on either simulations, MR- or CT-acquired anatomical reference images or phantom experiments [70, 71]. However, multiple challenges come with attempting to correct for the PVE, such as animal motion, dynamic tracer accumulation (and, hence, changing contrast ratios in the target region compared to the background), sequential multimodal imaging (i.e., registration errors due to a mismatch of the images based on motion), and low count rate statistics [70]. Thus, to our knowledge, no automatic PV correction is available for preclinical data at present.

Another important factor for receptor quantification using PET is the dose of radiotracer injected (Fig. 3d). Due to the limited sensitivity of the scanner, the injected dose of the radiotracer needs to be sufficient to obtain decent count rates. A high injected dose, however, comes with an increased amount of non-labeled ligand, which is dependent on the molar activity of the radiotracer (the ratio of tracer activity to mass) and can vary widely by synthesis (Fig. 3d and Table 1). High injected doses at low molar activity, especially in neuroreceptor studies, lead to high receptor occupancy and thus to competition of the radiotracer and the non-labeled ligand at the binding site (Fig. 3e). As previously mentioned, this can lead to pharmacological effects, thus violating the tracer principle [26], and can also compromise quantification accuracy due to reduced specific binding of radiolabeled compound. In order to obtain high quantification accuracy in rats and mice, it is highly important to keep the injected dose very low. Therefore, it is crucial to know over what range the specific binding is unaffected by the injected dose. These evaluations can be carried out using saturation binding experiments, in which an increasing mass is added to the tracer solution by keeping the injected activity constant. Using this dose-response relationship, the dose required to obtain $<1 \%$ receptor occupancy (tracer principle) can be determined from non-linear regression analysis. Through saturation binding experiments for $\left[{ }^{11} \mathrm{C}\right]$ raclopride, an injected 
dose of $<1 \mathrm{nmol} / \mathrm{kg}$ for rats [72] and $0.5 \mathrm{nmol} / \mathrm{kg}$ for mice [12] was estimated by others and in our studies. For $\left[{ }^{11} \mathrm{C}\right] \mathrm{DASB}$, we observed an injected dose of $<1 \mathrm{nmol} / \mathrm{kg}$ for rats, while low receptor occupancy could not be obtained in mice using high molar activities up to $116 \mathrm{GBq} / \mu \mathrm{mol}[11]$. In those experiments, receptor occupancy of less than 5-10\% could not be achieved; therefore, the values were obtained only by interpolation of the occupancy plot and need to be confirmed by in vivo experiments at higher molar activities. Ultra-high molar activities of 4000 $7000 \mathrm{GBq} / \mu \mathrm{mol}$ have been obtained by Nogushi et al. [73]. However, the molar activity levels in most published receptor studies are still between 50 and $200 \mathrm{GBq} / \mu \mathrm{mol}$. Enhancing the molar activity through improved tracer synthesis modules is therefore a major goal for PET receptor studies in small laboratory animals; this area of research will increase the receptor quantification accuracy of PET.

One major advantage of PET is the possibility to perform longitudinal investigations in the same animal. Thus, differences between animals due to inter-individual variations can be excluded. For this, it is assumed that differences between measurements in the same subject come from a pathological change or intervention. However, this assumption can only be made if the test-retest variability between two scans is low. The test-retest variability is heavily dependent on the radiotracer used in a study and therefore an important criterion to select a radiotracer for a particular target [74]. Low signal-to-noise ratios and off-target binding will lead to a higher variability between scans and thus differences of the same magnitude cannot be reliably detected. In addition, errors, which result from the postprocessing of data, including data reconstruction, correction, and co-registration to a standardized template as well as the estimation of binding parameters from simplified models have to be taken into account. If the test-retest variability for a given tracer, target region, and analysis method in the brain is high, changes cannot be reliably detected. Hence, higher numbers of animals are needed to gain statistically reliable results. To assess the influence of these limitations on the estimation of quantitative binding values and to determine the optimal quantification approach for a given PET tracer in small laboratory animals, test-retest experiments have been performed for several CNS PET ligands [11-13, 75-83]. In addition, physiological parameters can also vary within one animal at two different scan time points and may influence receptor availability, limiting the ability of PET to detect differences in an interventional study where a baseline and a treatment scan are compared. As a consequence, to increase the test-retest stability in a PET study, it is important to keep factors influencing the animal physiology including anesthesia, body temperature, heart rate, breathing rate, and stress constant and standardize imaging and post-processing protocols for a particular PET tracer.

Moreover, one important parameter in small-animal PET brain studies is the effect of scan duration on parameter stability. While longer scan times increase the signal-to-noise ratio and reduce the variability of parameter estimates, shorter scan times are desirable to reduce the effect of anesthesia on the animal physiology which can negatively impact binding parameter estimates. For example, a reduction in scan time from 120 to $70 \mathrm{~min}$ was proposed for the quantification of adenosine A1 receptors using $\left[{ }^{18} \mathrm{~F}\right] \mathrm{CPFPX}[84]$.

\section{Quantification of Receptor Binding}

Currently, many PET datasets are based on static PET measurements conducted at a fixed time point after a bolus injection of a PET tracer ignoring the holistic information about the tracer's pharmacokinetics. Therefore, the conclusions from these studies are drawn on the basis of semiquantitative approaches, e.g., using the standardized uptake value ratio (SUVR) as an outcome measure [85]. Although these semi-quantitative approaches may be useful and convenient to perform, they lack true image quantification and may be influenced by differences in tissue perfusion, vascularization, or differing levels of non-specific PET tracer uptake between or within experimental groups, the length of the uptake period, plasma glucose levels, plasma protein binding levels, and partial-volume effects [86, 87].

By contrast, dynamic PET scans together with mathematical compartment models describing the in vivo pharmacokinetics of the PET tracer allow quantification of the rates of physiological processes, such as perfusion or binding of a ligand to a neuroreceptor $[44,88,89]$. One of the standard compartmental models for the characterization of brain receptor PET tracers is the two-tissue compartment model (2TCM), which is, in fact, a simplification of the three-tissue compartment model (3TCM) (Fig. 4). The 3TCM assumes that the PET tracer freely defuses from the plasma to the tissue, where it can be free $\left(C_{F}\right)$, bound non-specifically $\left(C_{N S}\right)$, or bound to a specific receptor $\left(C_{\mathrm{B}}\right)$. However, kinetic modeling using three-tissue compartments is difficult due to the high number of rate constants to be estimated. Moreover, the $C_{F}$ and $C_{N S}$ fractions are kinetically indistinguishable, and thus, they are combined in a single compartment in the 2TCM [90]. This simplification requires an assumption that the equilibrium between the free and the non-specifically bound compartments is achieved rapidly. The $2 \mathrm{TCM}$ is described with the following differential equations:

$$
\begin{aligned}
& \frac{d C_{\mathrm{F}+\mathrm{NS}}(t)}{d t}=K_{1} C_{\mathrm{p}}(t)-\left(k_{2}{ }^{\prime}+k_{3}{ }^{\prime}\right) C_{\mathrm{F}+\mathrm{NS}}(t)+k_{4} C_{B}(t) \\
& \frac{d C_{B}(t)}{d t}=k_{3}{ }^{\prime} C_{\mathrm{F}+\mathrm{NS}}(t)-k_{4} C_{B}(t)
\end{aligned}
$$

where $C_{\mathrm{P}}(t)$ is the plasma concentration of the tracer over time and $K_{1}, k_{2}{ }^{\prime}, k_{3}{ }^{\prime}$, and $k_{4}$ are the transfer coefficients.

The total of $C_{\mathrm{F}+\mathrm{NS}}(t)$ and $C_{B}(t)$ corresponds to the tissue TACs and can be derived from the PET image, while $C_{\mathrm{P}}(t)$ must be measured in the blood during the PET measurement. The rate constants of the pharmacokinetic reactions $\left(K_{1}, k_{2}\right.$, $k_{3}$, and $k_{4}$ ) are estimated in the data analysis process, and the obtained values can be compared between the experimental groups [91, 92]. However, not only the rate constants but also the outcome parameter volume of distribution $\left(V_{\mathrm{T}}\right)$ can 

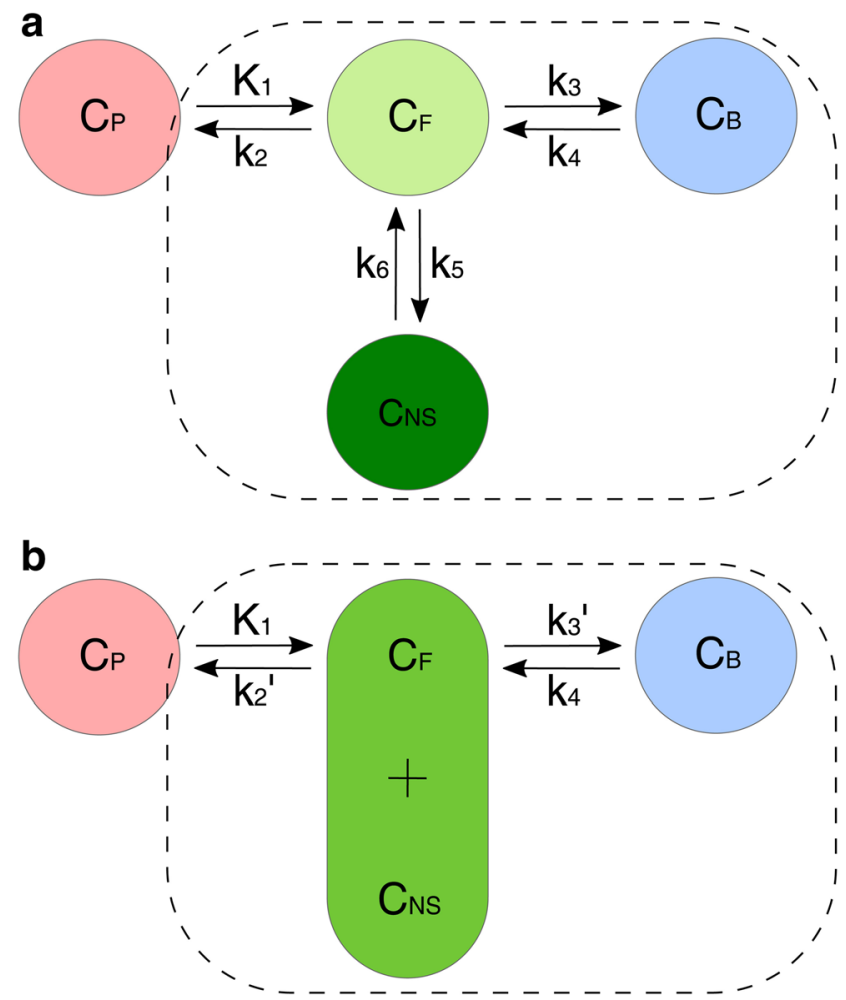

Fig. 4. Three-tissue compartment model for brain receptor studies with reversible radioligand binding. The PET signal is composed of different components: radiotracer in plasma $\left(C_{\mathrm{P}}\right)$, free radiotracer in tissue $\left(C_{\mathrm{F}}\right)$, radiotracer specifically bound to a receptor $\left(C_{\mathrm{B}}\right)$, and non-specifically bound radiotracer in tissue $\left(C_{N S}\right)$ (a). Since kinetic modeling using three-tissue compartments is difficult due to the large number of rate constants estimated, the model can be simplified to two-tissue compartments assuming a rapid equilibrium between the free and non-specifically bound compartments (b).

be derived from the ratio of compartmental rate constants and is generally used as primary outcome parameter as it is directly proportional to the receptor availability [93, 94]. For a two-tissue compartment model, $V_{\mathrm{T}}$ is derived as:

$V_{\mathrm{T}}=\frac{K_{1}}{k_{2}}\left(1+\frac{k_{3}}{k_{4}}\right)$

and is defined as the ratio of the radiotracer concentration in one region of the brain $C_{\mathrm{T}}$ to that in plasma $C_{\mathrm{P}}$.

$$
\begin{aligned}
& V_{\mathrm{T}=}=\frac{C_{\mathrm{T}}}{C_{\mathrm{P}}} \\
& C_{\mathrm{T}}=C_{\mathrm{B}}+C_{\mathrm{NS}}+C_{\mathrm{F}}
\end{aligned}
$$

However, despite the undeniable benefits of using fully quantitative methods for PET data analysis, these approaches impose also some challenges. As mentioned above, $C_{P}(t)$ must be measured using blood samples during PET acquisition. While blood sampling is relatively easy in patients, the procedure becomes difficult in rats and even more so in mice due to the limited blood volume $(\sim 20 \mathrm{ml}$ in rats and $\sim 1.5 \mathrm{ml}$ in mice). If too much blood is taken, physiological disturbances may occur [95].

As a way of circumventing this problem, a proposal has been made to record the radioactivity level in the blood circulating in an arterial-venous shunt with a blood counter [95] (Fig. 5). With the blood counter, the volume is preserved, the animal's physiology should remain stable, and the PET tracer remains in the system. Additionally, the high sampling rate of blood counters ensures accurate capturing of the peak activity following a bolus injection, which may be missed with manual sampling.

However, automated blood counting has also some disadvantages. Primarily, insertion of the arterial-venous shunt is a relatively complex procedure. Secondly, since the blood counter records the activity in the whole blood, the ratio of the PET tracer concentration in plasma to that in the whole blood $\left(\frac{p}{w b}\right)$ over time needs to be known in order to extract $C_{P}(t)[95$, 97]. Thus, if the technique is used to evaluate pharmacokinetics of a new PET tracer whose $\frac{p}{w b}$ ratio is unknown, collecting manual blood samples is unavoidable. In this respect, the recently introduced "CD-Well" has the advantage that small whole blood samples of $2-3 \mu \mathrm{L}$ can be collected into tiny Ushaped capillaries in which they are subsequently centrifuged to separate the plasma. The radioactivity concentration is measured using autoradiography [98]. This approach allows the $\frac{p}{w b}$ ratio to be calculated in mice.

Nevertheless, additional blood samples are still necessary to correct for the fraction of the tracer that has been metabolized in the plasma. This can be done with highperformance liquid chromatography (HPLC) or thin layer chromatography (TLC). Depending on the method and available equipment, relatively large volumes of plasma, and thus more animals, may be needed for this purpose. Preparation of samples for the chromatography analysis includes careful precipitation of plasma proteins. Moreover, in case of TLC, the measurement of the concentration of the metabolized tracer is not perfectly accurate, and hence, an error may be introduced. Consequently, in order to reduce the animal number and the workload, or to limit possible sources of errors, the metabolite correction is not always performed.

Finally, measuring blood and plasma activity, whether in a well-counter or an automated blood counter, requires careful cross-calibration of the external device with the PET scanner, including exact time matching. This procedure, as well as blood sampling and metabolite analysis described above, certainly makes full kinetic modeling more challenging compared to the semi-quantitative approaches, particularly by introducing more possibilities of additional errors to occur. Therefore, in smallanimal imaging, a compromise is sometimes required between applying corrections to reduce errors and to omit corrections which may introduce too much bias. 


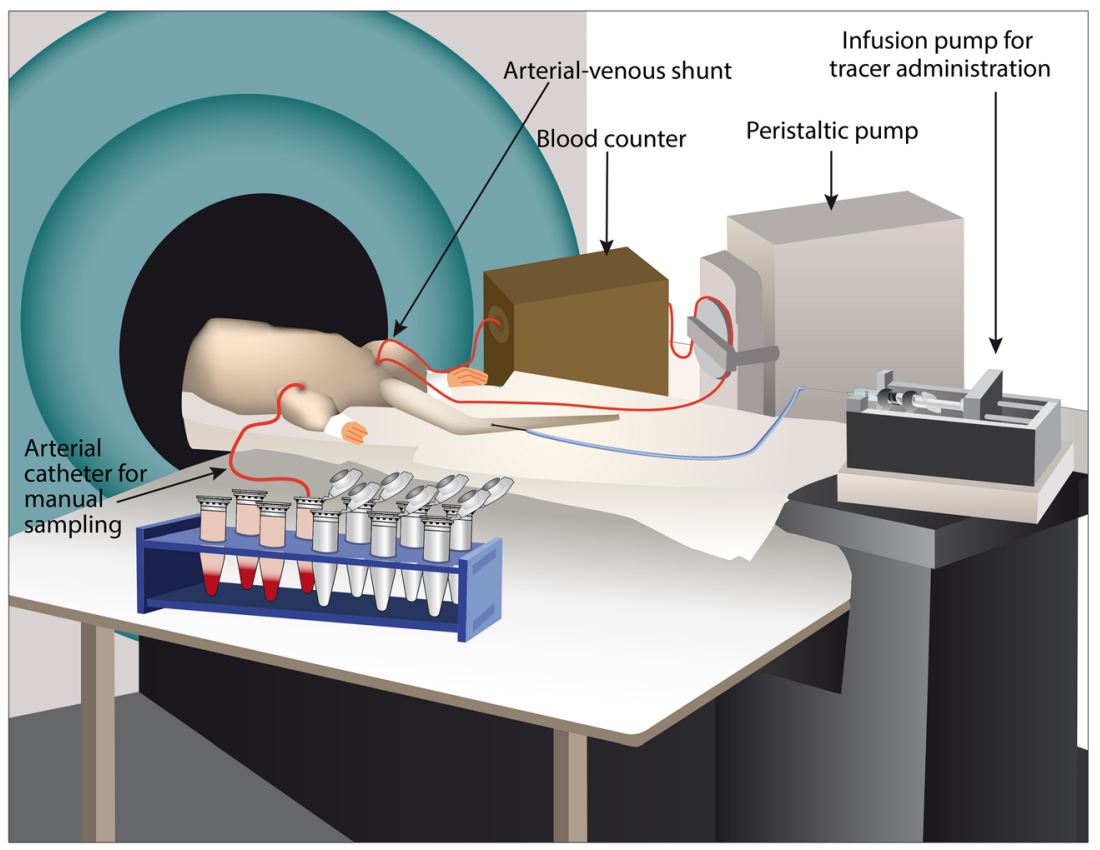

Fig. 5. Schematic illustration of an online blood counter setup and manual blood sampling to obtain an arterial input function from a rat. After the start of the PET acquisition, the radiotracer is injected via an infusion pump as a fast bolus, and the activity in the whole blood is counted using an online blood counting system. For this, a catheter is placed in the femoral artery of the animal and subsequently passes through the blood counter, in which the radioactivity from the blood is counted. The peristaltic pump ensures a constant and continuous blood flow through the arterial-venous shunt. Manual blood sampling can be conducted using an arterial catheter to correct the blood curve for the plasma free fraction and the contribution from metabolites (figure from [96]).

Alternatively to using invasive blood sampling, a PET image-derived arterial input function (AIF) can be applied with certain constraints [99]. This is done by extracting the TAC of the blood from a region of interest drawn on the left ventricle of the heart. However, it is crucial to remember that spillover and the PVE may substantially confound the measured values [97] and that appropriate corrections must therefore be applied [100]. Furthermore, as with the blood counter method, the value of $\frac{p}{w b}$ is necessary.

If the PET tracer binds to its receptor reversibly and if a region within the brain devoid of specific binding sites with similar non-specific binding as in the target region $\left(K_{1} / k_{2}\right.$ is the same) is available, then the input function from such a reference region can be used instead of $C_{P}(t)$. The specific binding can then be calculated from the volumes of distribution $\left(\mathrm{V}_{\mathrm{T}}\right)$ of the target and reference region. This is, especially in small-animal imaging studies, a decisive advantage over modeling approaches using the plasma input function as it is non-invasive, less labor-intensive and a less error-prone approach, since plasma metabolite corrections are not necessary. However, before a reference tissue model can be applied for a given PET tracer, blocking experiments are needed to ensure that a reference tissue has no specific binding sites and comparable non-specific binding. If a reference tissue is available, specific binding can be calculated from reference tissue compartment modeling [101]. To reduce the complexity of fitting four parameters with a full reference tissue model, simplified reference tissue models have been introduced which calculate only three parameters $\left(R_{1}, k_{2}\right.$, and $\left.\mathrm{BP}_{\mathrm{ND}}\right)$ [44]. The binding potential $\left(\mathrm{BP}_{\mathrm{ND}}\right)$ equals the ratio of the concentration of specifically bound tracer in tissue to the non-displaceable (ND) concentration.

The $\mathrm{BP}_{\mathrm{ND}}$ relates to the $V_{\mathrm{T}}$ :

$\mathrm{BP}_{\mathrm{ND}}=\frac{V_{\mathrm{T}}-V_{\mathrm{ND}}}{V_{\mathrm{ND}}}=\frac{V_{\mathrm{T}}}{V_{\mathrm{ND}}}-1=\mathrm{DVR}-1$

where $V_{\mathrm{ND}}$ is the distribution volume of the non-displaceable compartment and DVR is called the distribution volume ratio [94].

For example, the analysis of dynamic PET data from $\left[{ }^{11} \mathrm{C}\right]$ raclopride, which targets striatal D2/D3 receptors, can be performed using the simplified reference tissue model (SRTM) [44], in which the cerebellum is used as the reference region. The SRTM allows the level of specific binding to be evaluated by fitting the model function to the dynamic PET data, yielding estimates for fitting constants, such as the non-displaceable binding potential $\left(B P_{N D}\right)$ [94]. While this very elegant approach to obtaining quantitative values for the specific binding of a receptor ligand is adequate for $\left[{ }^{11} \mathrm{C}\right]$ raclopride, it cannot be used in every model organism without accounting for errors. For instance, it is not suitable for analyzing $\left[{ }^{11} \mathrm{C}\right] \mathrm{DASB}$, a reversibly 
binding serotonin transporter (SERT) ligand, because of the lack of an appropriate reference region. The entire cerebellum cannot be used in this case due to the presence of serotonergic projections in the cerebellar white matter [11]. Since the rat brain, and consequently the rat cerebellum, is larger in size, the obstacle of specific binding in the reference region can be surmounted by deriving TACs specifically from the cerebellar cortex, which lacks SERT; this solution, however, is not feasible for the mouse brain [11]. A reference region in the brain is also not available for the synaptic vesicle protein $2 \mathrm{~A}(\mathrm{SV} 2 \mathrm{~A})$ tracer $\left[{ }^{11} \mathrm{C}\right] \mathrm{UCB}-\mathrm{J}$. In such cases, using an invasively generated or imagederived AIF, as described above, is inevitable [102, 103].

Another important factor in small-animal imaging studies is the blood-brain barrier (BBB) penetration of PET tracers. If a PET tracer is a substrate of drug efflux transporters such as P-glycoprotein (P-gp) or multidrug resistance proteins (MRPs) that are expressed at brain capillary endothelial cells and astrocytic end-feet, the brain uptake can be very low leading to low signal-to-noise ratios and thus low reliability. The expression of these transporters has been shown to be higher in rodents than in humans and thus PET tracers, which have shown reasonable brain uptake in humans, only showed negligible brain uptake in rodents [104-107]. P-gp inhibition has shown increased brain uptake for several brain PET tracers in rodents using cyclosporine A (CsA) [105, $106,108,109]$. One example is $\left[{ }^{18} \mathrm{~F}\right]$ altanserin, a PET tracer for imaging 5-hydroxytryptamine type $2 \mathrm{a}$ receptors (5$\left.\mathrm{HT}_{2 \mathrm{~A}} \mathrm{R}\right)$. Brain uptake in rats was only $10 \%[110,111]$ in comparison to humans [112] and CsA treatment resulted in a two- to three-fold increased cerebral uptake of $\left[{ }^{18} \mathrm{~F}\right] \mathrm{altanserin}[106]$. It has been assumed that the effects of efflux transporters are similarly distributed across different brain regions. In terms of reference tissue modeling, the $\mathrm{BP}_{\mathrm{ND}}$ should therefore not change due to an increase of the radioligand uptake. However, changes of the $\mathrm{BP}_{\mathrm{ND}}$ between drug-naïve animals and CsA-treated animals have been reported, likely related to differences in the regional expression of the efflux transporter [104, 106]. Therefore, regional differences of drug-efflux transporter expression have to be carefully taken into account for the tracer quantification in rodents. In addition, if a tracer is a substrate of drug efflux transporters, altered P-gp function under pathological conditions in some diseases may influence the quantification and interpretation of tracer binding data and needs to be carefully evaluated.

Finally, species-dependent tracer metabolism has to be taken into account for PET studies in rodents [113, 114]. If a PET tracer is administered intravenously, several enzymes from blood and tissue will lead to metabolism of the parent PET tracer. Lipophilic radio-metabolites that enter the brain are undistinguishable from the parent PET tracer and will lead to biased parameter estimates. As the enzymatic profile between species is fairly different, with higher metabolism in lower organism, metabolic analysis across different species is important [115]. In rodents, metabolite formation is clearly detrimental as the determination is invasive and laborious. In vivo imaging of $\left[{ }^{18} \mathrm{~F}\right] \mathrm{FDOPA}$ to quantify dopamine (DA) turnover for example has been limited due to the complex formation of metabolites in the rat brain. However, Walker and colleagues [114] demonstrated the feasibility of $\left[{ }^{18} \mathrm{~F}\right]$ FDOPA PET imaging using a data-driven graphical analysis after applying inhibitors of the two main enzymes. Tracer defluorination is another major issue and species differences have also been reported for several PET tracers. While the mGluR5 receptor tracer $\left[{ }^{18} \mathrm{~F}\right] \mathrm{SP} 203$ is defluorinated in rats and monkeys, it shows no defluorination in humans $[116,117]$.

\section{Separate Determination of $B_{\text {avail }}$ and appK $_{d}$ in PET Receptor Studies}

Since the BP is defined as the product of receptor availability $\left(B_{\text {avail }}\right)$ and radiotracer affinity $\left(1 / \mathrm{appK}_{\mathrm{d}}\right)$ in vivo, a change in $\mathrm{BP}$ can reflect a change of $B_{\text {avail }}$, $\operatorname{appK}_{\mathrm{d}}$, or both [94]. Several methods have been described in the PET literature to determine the two values separately in small laboratory animals. The multiple ligand concentration receptor assay (MLCRA) is a multiple-injection approach derived from in vitro saturation binding experiments. The tracer and increasing amounts of the non-labeled compound are administered to the same animal, and at least four in vivo PET scans need to be performed. Hence, $B_{\text {avail }}$ and $a p p K_{d}$ can be obtained from the hyperbolic saturation curve by plotting the bound over the free tracer concentration (Fig. 6a), which can be calculated from the TACs of the target and reference regions $[119,120]$. However, if only four values are obtained from the in vivo experiments, linearization approaches are commonly used to avoid erroneous estimates of the curve fit (Fig. 6b). One major drawback of the MLCRA is that $B_{\text {avail }}$ and appK $\mathrm{d}_{\mathrm{d}}$ can be obtained only from multiple tracer injections, which must be performed on separate days and within a time window in which no receptor availability changes or occupancy from previous tracer injections are expected and animal recovery from anesthesia between scans is guaranteed. However, this can lead to inter-day variation of physiological conditions, such as cerebral blood flow and receptor availability states, affecting the quantification accuracy of $B_{\text {avail }}$ and $\mathrm{appK}_{\mathrm{d}}$.

For the purpose of avoiding inter-day variations between scans, a multiple-injection simplified reference tissue model (MI-SRTM) was developed to determine $B_{\text {avail }}$ and appK $\mathrm{d}_{\mathrm{d}}$ from a single PET scan with multiple tracer injections [121, 122]. Radiotracer injections are performed at intervals of 50 min using decreasing molar amounts of raclopride (1.5, 10 , and $30 \mathrm{nmol} / \mathrm{kg}$ ), and data are acquired for $150 \mathrm{~min}$. Quantitative values $\left(R_{1}, k_{2}\right.$, and $\left.\mathrm{BP}_{\mathrm{ND}}\right)$ are then estimated using the MI-SRTM. This approach reduces the stress for the animals, the variability, and the overall costs [122].

To further circumvent the problem of multiple tracer injections, Delforge et al. introduced a single-injection approach for the quantification of benzodiazepine receptors 

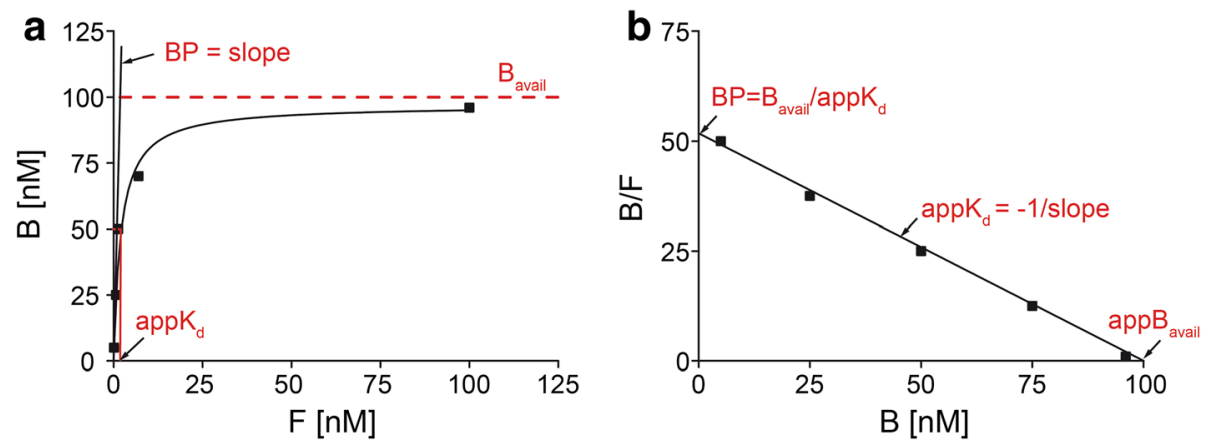

Fig. 6. Binding studies for the separate determination of $B_{\text {avail }}$ and $a p p K_{d}$. a The bound tracer concentration (B) is plotted over the free tracer concentration $(F)$ and results in a hyperbolic saturation curve with asymptote $B_{\text {avail. }}$. $A p p K_{d}$ is the amount of free ligand, necessary to saturate $50 \%$ of receptors. b Linearization of data points to display data by plotting B/F over B, resulting in a straight line with $x$-axis intercept $B_{\text {avail, }} y$-axis intercept $\mathrm{BP}$, and appK $\mathrm{K}_{\mathrm{d}}$ being the negative reciprocal of the slope (Scatchard plot) (adapted from [118]).

with $\left[{ }^{11} \mathrm{C}\right]$ flumazenil [123]. The method relies on the assumption that a dynamic equilibrium occurs during the time course of a PET experiment, resulting from the natural linear decrease in the bound concentration. This approach can be applied to PET tracers with fast kinetics and has already been used in rats [124] and mice [125, 126]. One advantage of partial-saturation over multiple-injection approaches is that the natural decrease in the bound tracer concentration over time leads to a comparably high number of data points, which reduces error proneness in the estimation of $B_{\text {avail }}$ and $a p p K_{\mathrm{d}}$.

However, one general challenge of all approaches is that the radiotracer must be injected at high doses leading to > $30 \%$ and sometimes up to $80 \%$ receptor occupancy, which violates the tracer principle and may bias the quantification due to compensatory changes in the receptor system under investigation. In addition, when a pharmacological challenge is applied, the receptor may be saturated from the endogenous neurotransmitter, leading to low numbers of available receptor sites and, therefore, to high tracer saturation. Moreover, after a pharmacological challenge, the system under investigation may not be in a steady state over the time frame of the PET experiment, and the quantification may therefore be biased. Thus, separate quantification of $B_{\text {avail }}$ and $\operatorname{appK}_{\mathrm{d}}$ with the methods described above is still very difficult, and results must be interpreted with care.

\section{Quantification of Neurotransmitter Release in Rodents}

Dysregulation of neurotransmitter signaling is involved in many neuropsychiatric and neurodegenerative disorders. Currently, the gold standard method for quantifying neurotransmitter changes in the synaptic cleft is in vivo microdialysis, which allows the quantification of neurotransmitter variations in the range of $15-20 \%$ from baseline with nanomolar sensitivity. However, in contrast to PET, microdialysis experiments are very invasive, can only be used to measure neurotransmitter changes in distinct areas of the brain, and have severely limited temporal resolution (one sample every 10 to $20 \mathrm{~min}$ ). Therefore, in vivo PET imaging of neurotransmitter release is increasingly being used to noninvasively quantify neurotransmitter concentration changes in the rodent brain. PET quantification of neurotransmitter changes, however, can be obtained only by indirect methods, as a direct detection of endogenous neurotransmitters is not possible. Two main models to describe the PET signal changes after a pharmacological challenge have been described in the literature: the occupancy model, in which a PET receptor tracer and the neurotransmitter compete for the same binding site on the receptor [127], and the internalization model, in which increased neurotransmitter concentrations lead to agonist-induced receptor internalization at the postsynaptic membrane [128].

Using the high-affinity D2/D3 receptor antagonist PET ligand $\left[{ }^{18} \mathrm{~F}\right]$ fallypride in occupancy studies with increasing amphetamine doses ( 0.1 to $2.5 \mathrm{mg} / \mathrm{kg}$ ), a dosedependent decrease in $\left[{ }^{18} \mathrm{~F}\right]$ fallypride $\mathrm{BP}_{\mathrm{ND}}$ ranging from $2.4 \%$ to $17.9 \%$ after the release of 38.3 to $434.3 \mathrm{fmol}$ of DA ( 1.5- to 17-fold increase) in the striatum was observed [129]. This decrease in $\left[{ }^{18} \mathrm{~F}\right]$ fallypride $\mathrm{BP}_{\mathrm{ND}}$ followed a hyperbolic saturation curve. Thus, changes in DA release greater than 20 -fold will not lead to higher PET signal changes. Similar experiments have been performed for the D2/D3 receptor antagonist PET ligand $\left[{ }^{11} \mathrm{C}\right]$ raclopride using a RATPET small-animal scanner (spatial resolution of $2.4 \mathrm{~mm}$ FWHM) [130]. In microdialysis experiments, Hume et al. observed a $16 \%$ reduction of $\left[{ }^{11} \mathrm{C}\right]$ raclopride $\mathrm{BP}_{\mathrm{ND}}$, which was associated with an approximately 25 -fold increase in extracellular DA [131]. A maximum reduction of $21 \%$ in $\left[{ }^{11} \mathrm{C}\right]$ raclopride $\mathrm{BP}_{\mathrm{ND}}$ was observed at a high amphetamine concentration of $4 \mathrm{mg} / \mathrm{kg}$, which induces an increase in extracellular DA by approximately 30 -fold [132]. However, this change was not significantly different from the one induced by a $2-\mathrm{mg} / \mathrm{kg}$ dose. Using a higher-resolution quad-HIDAC system with a spatial resolution of $\sim 1.5 \mathrm{~mm}$ FWHM, a maximum reduction of 
approximately $30 \%$ in $\left[{ }^{11} \mathrm{C}\right]$ raclopride $\mathrm{BP}_{\mathrm{ND}}$ was observed, pointing to a possible impact of scanner spatial resolution and sensitivity [130]. In contrast to the DA concentration, which usually peaks approximately $10 \mathrm{~min}$ after intravenous injection, changes in $\left[{ }^{11} \mathrm{C}\right]$ raclopride $\mathrm{BP}_{\mathrm{ND}}$ have been shown to persist over several hours, suggesting that receptor internalization is involved in amphetamine-induced changes in radiotracer binding $[130,133]$. To distinguish DA receptor occupancy from receptor internalization, Skinbjerg et al. used arrestin-3 knockout mice, which are incapable of internalizing D2 receptors [134]. Four hours after amphetamine administration, radiotracer binding returned to baseline in knockout but not wild-type mice, confirming receptor internalization after DA displacement by amphetamine.

In order to increase the sensitivity of PET radiotracers to DA, agonist radiotracers such as $\left[{ }^{11} \mathrm{C}\right] \mathrm{NPA}$ [135], $\left[{ }^{11} \mathrm{C}\right]$ PHNO [136], and $\left[{ }^{11} \mathrm{C}\right] \mathrm{MNPA}[137]$ have been developed. These agonist radiotracers bind to the D3 receptor and the high-affinity state of the D2 receptor and show higher sensitivity to extracellular DA changes than the antagonist radiotracer $\left[{ }^{11} \mathrm{C}\right]$ raclopride in animals and humans [138-140].

In contrast to the dopaminergic system, imaging of other neurotransmitter systems has been more challenging in the past. Regarding the serotonergic system, several promising candidates have been shown to be ineffective for quantifying serotonin (5-HT) release [128]. However, recent studies using PET radiotracers for the 5-HT2A receptor [141] and the 5-HT1B receptor [142] in the pig brain have shown promising results concerning the quantification of 5-HT release. Pharmacological intervention with $0.5 \mathrm{mg} / \mathrm{kg}$ fenfluramine, which induces an average six- to eightfold increase in cerebral interstitial 5-HT release compared to baseline in the medial prefrontal cortex [141, 143], resulted in only a $16 \%$ change in $\left[{ }^{11} \mathrm{C}\right] \mathrm{AZ} 10419369$ [142] but a $46 \%$ change in $\left[{ }^{11} \mathrm{C}\right] \mathrm{Cimbi}-36$ [141]. This means that $\left[{ }^{11} \mathrm{C}\right] \mathrm{Cimbi}-36$ is over three times more sensitive to 5 -HT than $\left[{ }^{11} \mathrm{C}\right]$ raclopride is to DA. Studies in rats or mice will need to confirm whether it is feasible to use this PET tracer to measure 5-HT release in rodent models of neurological disorders.

In the last few years, quantification of endogenous noradrenaline (NA) levels has increasingly come into focus. Recent studies have focused on PET radiotracers for $\alpha 2$-adrenoreceptors such as $\left[{ }^{11} \mathrm{C}\right]$ yohimbine [144] and $\left[{ }^{11} \mathrm{C}\right] \mathrm{ORM}-13070$ [145]. $\left[{ }^{11} \mathrm{C}\right]$ Yohimbine, for example, has been shown to be a surrogate marker of NA release in rats [146] and pigs [144] by showing a significant decrease in the $\mathrm{V}_{\mathrm{T}}$ in response to amphetamine challenge. For example, acute amphetamine injection of $2 \mathrm{mg} / \mathrm{kg}$ induced a $\mathrm{BP}_{\mathrm{ND}}$ change of $\sim 38 \%$ in rats [146]. However, the quantification of $\alpha 2$-adrenoreceptors and endogenous NA in rodent models with kinetic modeling still remains difficult due to the distribution of the receptors throughout the whole brain, leaving no appropriate reference region.
Adenosine is an extracellular signaling molecule, which is released from neurons and glia cells during inflammation [147] and modulates the release of other neurotransmitters [148]. Adenosine fulfills its function by stimulating $G$ protein-coupled adenosine receptors and shows highest affinity to $A_{1}$ and $A_{2 A}$ receptors [148]. Selective PET targeting $A_{1}$ and $A_{2 A}$ receptors have been developed [149153], but to our knowledge, sensitivity to endogenous adenosine has not been observed in vivo. However, in binding assays, using human brain homogenates and $\mathrm{CHO}$ cells transfected with the $\mathrm{A}_{1}$ receptor $\left[{ }^{3} \mathrm{H}\right] \mathrm{CPFPX}$ was displaced by high adenosine concentrations to the level of non-specific binding [154]. In a recent study, Guo et al. evaluated a partial agonist radiotracer for the adenosine $A_{1}$ receptor in rats, which showed good BBB penetration, a high specificity, and subtype selectivity being a promising candidate to measure variations of the endogenous neuromodulator adenosine in vivo [155].

As the number of novel PET receptor ligands increases, more promising candidates will become available to quantify other neurotransmitter systems, such as the GABA and glutamate (GLU) systems, in the brain. This will be an enormous gain for future applications of in vivo neurotransmitter-release PET imaging.

\section{Animal Models}

Recent years have brought rapid development of transgenic and toxin-induced animal models, which provide many insights in the pathophysiology, progression, and treatment of neurological diseases [156-159]. The latest advances in genome engineering methodologies based on the clustered regularly interspaced short palindromic repeats (CRISPR)/ Cas9 system provide a novel molecular tool that, via knockout, overexpression, and mutation of genes, resemble disease phenotypes with increased accuracy and link specific genes to molecular changes [160-162]. CRISPR/Cas9 expedites the generation of transgenic animals, and several tools are under investigation to optimize the in vivo delivery to the brain. Currently, adeno-associated viral (AAV) vectors represent the most tempting approach due to their tissue spreading, stable transgene expression, versatility, mild toxicity, and translational potential [160, 161, 163]. Genetic modifications have been demonstrated by direct injections in the mouse brain $[161,164-166]$ and recently in the rat brain [167]. Indeed, a novel Huntington disease (HD) mouse model has been generated by AAV-CRISPR striatal injections efficiently targeting and inactivating the mutant Htt allele [168]. Furthermore, this powerful geneengineering technology expands the possibilities for disease modeling to large animal species such as pigs and nonhuman primates [169-171], in which gene editing has been challenging until now.

Chemogenetics might be used if a more naturalistic stimulation is preferred to complete protein expression. Indeed, Designer Receptors Exclusively Activated by Designer Drugs 
(DREADDs) have been engineered from native receptors to respond solely to a specific ligand, mimicking the endogenous stimulation of a receptor through neurotransmitters. This approach allows for the selective regulation and identification of neuronal circuitry and signals that specify social behaviors [172], addiction [173], and feeding [174-176]. Major drawbacks of the system are the off-target effects on wild-type DA, HIS, and 5-HT receptors arising from the in vivo retro-conversion of the DREADD-ligand Clozapine- $N$-Oxide (CNO) to Clozapine $[177,178]$. These can be avoided injecting the CNO intracranial [179] or using the compound 21 as DREADD-ligand [180]. Provided with the appropriate control group, which does not express DREADDs but receives the ligand, DREADDs can be considered a powerful strategy to dissect pathways involved in neurodegenerative diseases [181-184]. Recently, DREADD technology has been coupled to $\left[{ }^{18} \mathrm{~F}\right]$ FDG-PET (DREAMM) to map non-invasively the regional or global effects mediated by the DREADD stimulation in targeted cells $[185,186]$.

Among all neuroimaging modalities, PET offers the highest degree of sensitivity and allows the quantitative evaluation of receptors, transporters, neurotransmitters, and aggregated proteins in the brains of transgenic animals [187, 188]. Imaging of aggregated proteins has been successfully shown in mouse models of AD [189-192]. In contrast to the situation in AD, however, there is not yet an available PET tracer to assess alphasynuclein pathology in the brains of humans and animal models of PD. Thus, research has focused on pre- and postsynaptic dopaminergic transporters and receptors to distinguish PD from related disorders or to quantify therapeutic effects [193, 194]. Compensatory mechanisms in PD, which occur to counterbalance the dopaminergic loss, can be observed with PET before the symptoms occur. Indeed, decreased binding of presynaptic markers such as $\left[{ }^{11} \mathrm{C}\right]$ methylphenidate, $\left[{ }^{18} \mathrm{~F}\right] \mathrm{DOPA},\left[{ }^{11} \mathrm{C}\right] \mathrm{CFT}$, and $\left[{ }^{11} \mathrm{C}\right] \mathrm{DTBZ}$ and increased $\left[{ }^{11} \mathrm{C}\right]$ raclopride binding to postsynaptic $\mathrm{D} 2 / \mathrm{D} 3$ receptors have been reported in asymptomatic toxin-lesioned $[195,196]$ and transgenic rats [197].

$\left[{ }^{18} \mathrm{~F}\right] \mathrm{FDG}$ and $\left[{ }^{11} \mathrm{C}\right]$ raclopride PET highlights pathological alterations before the onset of clinical symptoms in HD [198, 199]. Toxin-induced HD rodent models have been extensively characterized by PET, showing reductions in DA D2 and adenosine 2A receptor occupancy [153, 200]. Conversely, no PET in vivo imaging studies have been performed to date in preclinical rodent models of schizophrenia, with only one recent imaging publication using fMRI [201]. With several reports showing that the GLU excitatory neurotransmission, via NMDA receptor activation, contributes to schizophrenia [202], PET imaging represents a major research area in this field and has very likely a huge potential for clinical translation.

PET imaging plays also a key role in evaluating the efficacy of gene therapy, which currently constitutes one of the most appealing treatment approaches [203, 204]. Hence, PET radionuclides coupled to reporter genes have been successfully developed to monitor gene expression over time [205-208].

\section{Application of Simultaneous PET/MRI to Investigate Neurotransmitter- Receptor Interactions}

A major strength of multimodal imaging is the concerted application of a variety of imaging methods to measure similar or distinguished biochemical and morphological states. The combination of PET and MRI (PET/MRI) devices was proposed in the 1990 [209-211]; however, fully elaborated small-animal systems [212, 213] were developed 10 years later. Historically, the development of multimodal imaging strategies originates from the need to match functional and morphological information. Due to the availability of valid morphological rodent brain atlases and the fact that the brain is well embedded in the skull, simultaneous data acquisition may not always need to study static receptor availability. However, if functional processes change dynamically during the acquisition, for example, as a result of interventions altering brain function, simultaneous acquisitions can be inevitable for obtaining complementary information of both imaging modalities [214].

In a preclinical setting, this was first demonstrated by Wehrl et al. [214], where our group reported a simultaneous PET/MRI study of brain function in response to a whisker stimulation in rats. Here, $\left[{ }^{18} \mathrm{~F}\right]$ FDG-PET was applied to trace changes in glucose metabolism on a slow time scale, while functional MRI (fMRI) simultaneously assessed fast vascular and oxygenation changes. Based on this multifunctional dataset, Wehrl et al. reported spatial and quantitative discrepancies between the PET and the fMRI activation profiles, revealing comprehensive and complementary information of both modalities.

The unique benefit of simultaneous PET/MRI with regard to functional neuroimaging is the high temporal correlation of data revealed from both imaging modalities. This has a variety of advantages, since functional neurotransmitter processes can be monitored at the same time using PET and fMRI techniques to investigate multiple stages of neurotransmitter-receptor plasticity [215] (Fig. 7). Thus, PET/MRI is capable of monitoring in vivo processes on various levels, e.g., brain activation can be monitored using the blood oxygen level-dependent (BOLD) effect with fMRI while changes in receptor plasticity or blood flow are being monitored by PET [216, 217]. A simultaneous PET/MRI study in nonhuman primates by Sander et al. [217] investigated the relation ship between changes in D2/D3 DA receptor occupancy measured by PET and changes in brain activity obtained by fMRI. Here, similar temporal profiles were observed for specific $\left[{ }^{11} \mathrm{C}\right]$ raclopride binding estimates and changes in cerebral blood volume inferred by fMRI. Overall, this multifunctional dataset demonstrated the utility of simultaneous PET/fMRI to correlate neurochemical profiles with hemodynamic changes, paving the way for in vivo studies of different receptor systems in the healthy and diseased rodent brain. 


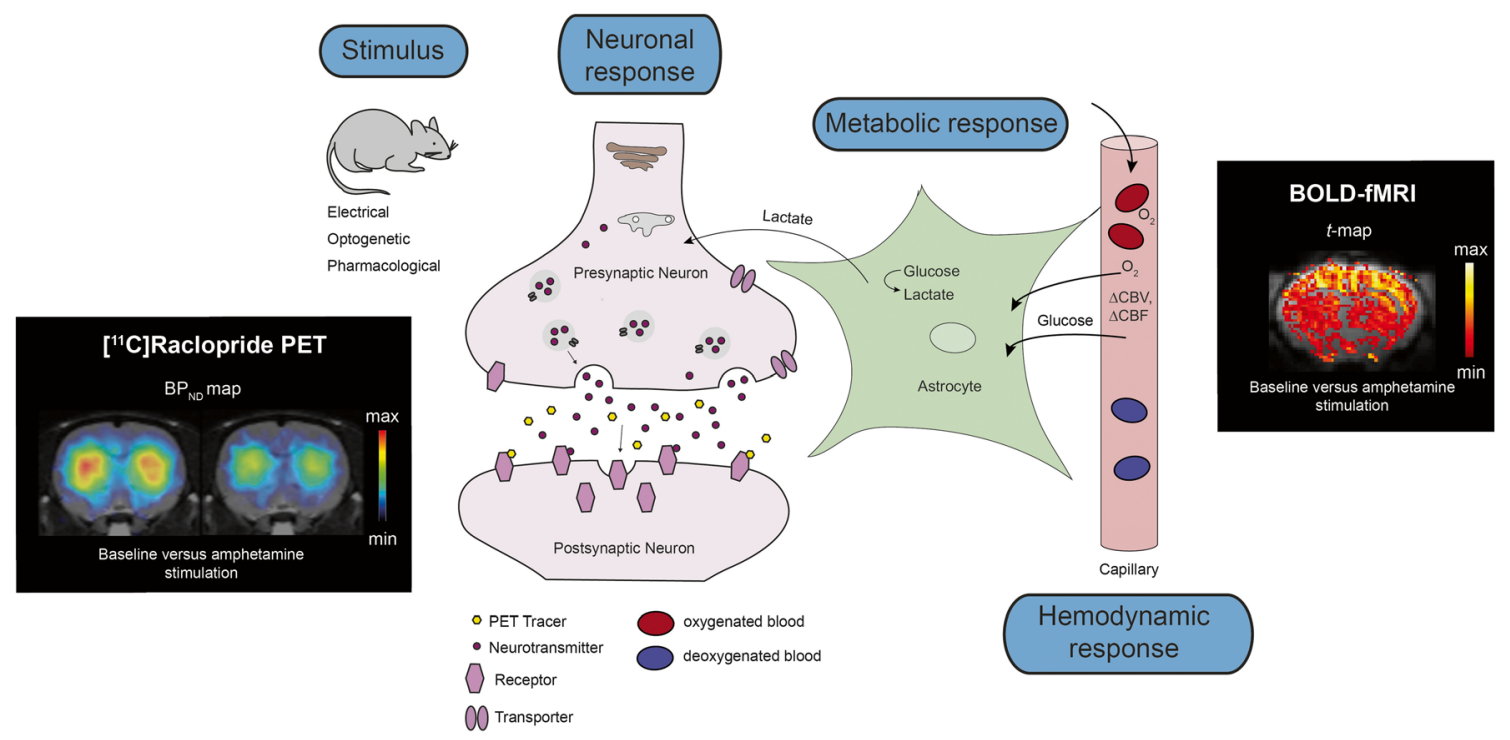

Fig. 7. Schematic illustration of mapping neuronal activity using simultaneous PET/BOLD fMRI. After a stimulus is applied, the neuronal response can be obtained from changes in receptor occupancy levels using PET imaging of synaptic neurotransmitter release. Images show changes in $\left[{ }^{11} \mathrm{C}\right]$ raclopride PET signal, a D2/D3 receptor antagonist, in the striatum after pharmacological stimulation with the dopamine-releasing drug amphetamine in one rat. The hemodynamic response of the same animal is obtained at the same time from changes in cerebral blood flow, blood volume, and blood oxygenation using blood oxygen level-dependent (BOLD) fMRI contrasts. $T$-map (baseline versus stimulation) is shown in the right image after a pharmacological stimulation with D-amphetamine.

However, from a methodological point of view, simultaneous imaging might be limited by the fact that PET tracers have certain uptake characteristics that often make direct, truly simultaneous acquisition difficult. Furthermore, the cost and space requirements of simultaneous PET/MRI systems need to be considered. Nevertheless, simultaneous PET/MRI holds great potential to further decode brain function on multiparametric levels, which might directly contribute to the investigation of neurological pathologies, especially in the field of neurodegenerative and psychological disorders.

\section{Quantitative Receptor Imaging in Clinical Translation}

The technological advancement of preclinical systems and the development of specialized neurotracers have positively translated into the clinical field. However, in order to successfully translate these findings into the human scenario, it is necessary to maintain constant scrutiny of experimental conditions in humans and animal experiments in order to accurately progress in the translational field. The clinical neuroimaging field has advanced substantially since the implementation of $\left[{ }^{18} \mathrm{~F}\right] \mathrm{FDG}$ for evaluation of glucose metabolism in the brain [218-220]. Over 5000 PET/CT systems have been installed worldwide, which will likely lead to implementation of more experimental tracers and hopefully help the development of personalized medicine. The field has been further boosted by an increased number of clinical PET/MRI systems, including until recently a whole-body human PET system. This has motivated multidisciplinary groups composed of radiochemists, neurobiologists, and neuroimaging scientists in the preclinical and clinical areas to focus on "bench-to-bedside" evaluations of specific receptor subtypes in multiple tissues and diseases. Thus, clinical neuroimaging has certainly matured due to these technological milestones and the synergistic advances of these fields.

Beyond the glucose analog $\left[{ }^{18} \mathrm{~F}\right] \mathrm{FDG}$, there is a large number of dedicated neuroimaging tracers in the preclinical pipeline that have been translated into Phase I clinical trials. There have been remarkable increments in the application of radiotracers in the fields of clinical neuroscience, neurology, psychology, and psychiatry in the last 10 years. However, it is still seldom the case that a PET tracer reaches financial stability and enters clinical diagnostic routine. Here, we mention several examples of different targets that have translated, reaching clinical routine and others that have made it to the experimental human setting. After years of preclinical development, $\left[{ }^{18} \mathrm{~F}\right]$ florbetaben, $\left[{ }^{18} \mathrm{~F}\right]$ florbetapir, and $\left[{ }^{18} \mathrm{~F}\right]$ flutemetamol were approved by the U.S. Food and Drug Administration and the European Medicines Agency to evaluate $\beta$-amyloid neuritic plaque density in patients with cognitive impairment [221-223]. Also, recently, $\left[{ }^{18} \mathrm{~F}\right] \mathrm{MK}-$ 6240 , which was designed for quantifying the brain burden of neurofibrillary tangle (NFT) pathology and originally evaluated in brains of non-human primates [224], has also completed Phase I of clinical trials. It has consistently shown increased uptake in the regions associated with NFT deposition in $\mathrm{AD}$ [225]. Other radiotracers have been 
developed and characterized in animal models but have taken a significant amount of time to reach human experiments.

Tracers synthesized for neuroimaging have a wide range of usages, e.g., specifically targeting neurotransmitter synthesis, receptor, release or transport, BBB permeability, or neuroinflammation to measure enzymatic activity and general ligand availability [226]. Some tracers are better known than others. For instance, due to the early production availability in radiopharmacies of DA D2 receptor tracers such as $\left[{ }^{11} \mathrm{C}\right]$ raclopride and later $\left[{ }^{18} \mathrm{~F}\right]$ fallypride for $\mathrm{D} 2 / 3$ receptors, there is a relatively robust understanding of the dopaminergic system [227]. This knowledge comes to a very large extent from preclinical evaluations performed in rodents [12, 82, 228, 229].

Some other tracers have allowed a good understanding of the physiological roles of important receptor families, such as the 5-HT receptors. Plenty of work has been performed preclinically in order to characterize this family of receptors, which has slowly translated into clinical experiments. It has been 10 years since $\left[{ }^{11} \mathrm{C}\right] \mathrm{SB} 207145$ was first shown in the brains of pigs in vivo [230]. Recently, it has been revealed that reduced binding to the cerebral 5-HT4R shows a positive correlation with aggressive behavior in men [231]. Likewise, $\left[{ }^{11} \mathrm{C}\right] \mathrm{AZ} 10419369$, originally characterized in non-human primates [232], has also recently been used to find a positive correlation between reduced binding of 5HT1B and the time since the last migraine onset [233]. GLU tracers have shown reduced availability of the type 1 metabotropic GLU receptor (mGluR1) in patients with hereditary and sporadic cerebellar ataxia, which now is proposed as a specific imaging biomarker of the disease [234]. A tracer targeting the $\kappa$-opioid receptor was evaluated in non-human primates for the first time, potentially providing a novel tool to investigate this system in humans [235]. Another example is the $18-\mathrm{kDa}$ translocator protein (TSPO) tracer, which has been used to provide preliminary imaging data on neuroinflammation in non-human primates [236] and in patients [237, 238]. Overall, a wide range of neurotransmitter systems, neuropsychological diseases associated with neurotransmitter imbalance, and brain-specific targets can be studied using PET, providing an increasingly detailed understanding of the normal and pathological human brain. However, in order to ensure the congruent translation of these receptor availabilities between species, we must attempt to close the gap between the experimental conditions between humans and animals.

A major complication for translation in preclinical studies is the use of anesthetics. Anesthetics have effects not only in vasodilation or perfusion [239] but also on receptor binding in the brain [240-242]. Animal brain receptor experiments are often performed under anesthesia due to the difficulty or impossibility of training an animal to remain immobile during the scan. This mismatch between preclinical and clinical experiments can potentially lead to a high range of uncertainty in translational studies. In order to circumvent this challenge, new technologies have been developed in the past years to evaluate animals in an awake state.

Takuwa et al. [243] developed a system for imaging an awake mouse by restraining the cranium onto an acrylic head-holder, while the animal was able to move its legs freely on a Styrofoam ball. This innovative approach effectively showed that there were significant differences in the binding potential of $\left[{ }^{11} \mathrm{C}\right]$ raclopride in free-walking awake mice, in comparison to isoflurane-anesthetized mice and whole-body-restrained awake mice. Another method was developed by Miranda et al. in 2017 [244], consisting on the tracking of a rodent head by attaching four-point sources onto it, in combination with a complex reconstruction algorithm. The animal was placed on a cylindrical transparent tube and allowed move freely in the container during the scan. The approach was further validated using mice, where the authors found that mementine led to a 2.6 larger $\left[{ }^{18} \mathrm{~F}\right] \mathrm{FDG}$ uptake on awake animals in comparison to anesthetized animals [245]. Kyme et al. [246] further investigated the field of awake-animal imaging by using an automated motion-tracking robot in combination with motion correction approaches and placing a visual marker on the animal's head. The robot performed accurate and responsive movements in order to real-time correct the animal's alignment to the center of the FOV. In these experiments, open-field observations were also annotated after the administration of amphetamine, which was successfully corrected for motion artifacts. The behavioral data was obtained simultaneously to the PET acquisition which provided congruent real-time information. Altogether, the field of awake-animal scanning has the potential to modify many receptor tracer paradigms and should be followed closely. The novel techniques will likely further develop the field of animal brain imaging and help reduce the incongruences between animal and human data. Before PET tracers can be routinely applied in clinical diagnostics, convergence of the results among different human trials is required. To improve this translational process, clinical neuroreceptor imaging studies must attempt to meet the standards of experimental design that the preclinical field proposes. Clinical research is inevitably less standardized than the controlled environment of the preclinical field, leaving plenty of work for translational scientists. This is exemplified by a recent meta-analysis of human schizophrenia studies performed with $\left[{ }^{11} \mathrm{C}\right]$ flumazenil, a tracer targeting $\mathrm{GABA}_{\mathrm{A}}$ receptors, which showed inconsistencies in reduced brain region uptake among the studies [247]. The authors remark that these results contrast with those of preclinical studies, which suggest that benzodiazepines can help prevent the neuroanatomical and neurophysiological dysfunctions related to schizophrenia [247]. Of course, there are inherent differences between species, but the variance among human studies suggests inconsistency of experimental design in the clinic. Likewise, preclinical scientists must consciously improve methods and implement more accurate animal models in order to have a 
close pathophysiological resemblance to the human disease and obtain translatable results.

\section{Conclusion and Outlook}

The clinical application of tracers that have been translated to the clinical field from preclinical laboratories shows that preclinical research can deliver clinical solutions. Despite some physical limitations inherent to PET imaging, it is now possible to quantify receptor-binding parameters in laboratory animals in a reproducible and reliable manner. An absolute quantification in rats and mice is difficult, but BP changes larger than $10 \%$ can be reproducibly quantified in vivo in the picomolar range in large brain regions with high receptor availability, such as the striatum, cortex, and thalamus $[12,13]$. One crucial point in rodent imaging studies is the standardization of the experimental protocols and analysis [248]. Different evaluation and analysis methods of the same data can lead to very different results, explaining the large discrepancies among results and often rendering it very difficult to compare results from different laboratories. For this reason, future PET studies should apply strict standardization not only to the study conditions, including protocols, image reconstruction, and correction methods (Table 1), type of anesthesia, and injected tracer dose, but also to the analysis methods to improve the comparability of the performed experiments.

A major gap between preclinical imaging research and clinical translation is the required anesthesia for PET and MR preclinical imaging studies. Changes in anesthetic states can influence imaging outcomes, especially if multimodal functional and molecular information are acquired [249]. The same applies to the role of body temperature stabilization. Indeed, changes in body temperature can influence cerebral blood flow and, hence, the results obtained in PET and MR functional measurements [250]. For this reason, animal PET scanners for freely moving animals are under development to reduce the influence of different anesthesia regimes.

Although the use of PET alone does not allow the absolute quantification of receptor and neurotransmitter changes, its application in combination with other ex vivo methods, such as immunohistochemistry, autoradiography, HPLC and microdialysis, has provided an enormous gain in scientific knowledge. In addition, it allows longitudinal in vivo investigation in the same subject, thus reducing the number of experimental animals involved in the study, increasing the statistical reliability of the data, and supporting the translation of preclinical results into clinical applications [251, 252].

\section{Compliance with Ethical Standards}

\section{Conflict of Interest}

The authors declare that they have no conflicts of interest.
Open Access This article is distributed under the terms of the Creative Commons Attribution 4.0 International License (http:// creativecommons.org/licenses/by/4.0/), which permits unrestricted use, distribution, and reproduction in any medium, provided you give appropriate credit to the original author(s) and the source, provide a link to the Creative Commons license, and indicate if changes were made.

\section{References}

1. Sasaguri H, Nilsson P, Hashimoto S et al (2017) APP mouse models for Alzheimer's disease preclinical studies. EMBO J 36:2473-2487

2. Creed RB, Goldberg MS (2018) New developments in genetic rat models of Parkinson's disease. Mov Disord. https://doi.org/10.1002/ mds. 27296

3. Koprich JB, Kalia LV, Brotchie JM (2017) Animal models of alphasynucleinopathy for Parkinson disease drug development. Nat Rev Neurosci 18:515-529

4. Pouladi MA, Morton AJ, Hayden MR (2013) Choosing an animal model for the study of Huntington's disease. Nat Rev Neurosci 14:708-721

5. Chadman KK (2017) Animal models for autism in 2017 and the consequential implications to drug discovery. Expert Opin Drug Discov 12:1187-1194

6. Nielsen J, Fejgin K, Sotty F et al (2017) A mouse model of the schizophrenia-associated 1q21.1 microdeletion syndrome exhibits altered mesolimbic dopamine transmission. Transl Psychiatry 7:1261

7. Kaiser T, Feng G (2015) Modeling psychiatric disorders for developing effective treatments. Nat Med 21:979-988

8. Cherry SR (2001) Fundamentals of positron emission tomography and applications in preclinical drug development. J Clin Pharmacol 41:482-491

9. Cherry SR, Gambhir SS (2001) Use of positron emission tomography in animal research. ILAR J 42:219-232

10. Fang XT, Eriksson J, Antoni G et al (2017) Brain mGluR5 in mice with amyloid beta pathology studied with in vivo $\left[{ }^{11} \mathrm{C}\right] \mathrm{ABP} 688$ PET imaging and ex vivo immunoblotting. Neuropharmacology 113:293300

11. Walker M, Ehrlichmann W, Stahlschmidt A et al (2016) In vivo evaluation of ${ }^{11} \mathrm{C}$-DASB for quantitative SERT imaging in rats and mice. J Nucl Med 57:115-121

12. Fischer K, Sossi V, Schmid A et al (2011) Noninvasive nuclear imaging enables the in vivo quantification of striatal dopamine receptor expression and raclopride affinity in mice. $\mathrm{J}$ Nucl Med 52:1133-1141

13. Fischer K, Sossi V, von Ameln-Mayerhofer A, Reischl G, Pichler BJ (2012) In vivo quantification of dopamine transporters in mice with unilateral 6-OHDA lesions using $\left[{ }^{11} \mathrm{C}\right]$ methylphenidate and PET. Neuroimage 59:2413-2422

14. Sossi V, Dinelle K, Jivan S et al (2012) In vivo dopamine transporter imaging in a unilateral 6-hydroxydopamine rat model of Parkinson disease using ${ }^{11} \mathrm{C}-$ methylphenidate PET. J Nucl Med 53:813-822

15. Phan JA, Landau AM, Jakobsen S, Gjedde A (2017) Radioligand binding analysis of alpha 2 adrenoceptors with $\left[{ }^{11} \mathrm{C}\right]$ yohimbine in brain in vivo: extended inhibition plot correction for plasma protein binding. Sci Rep-UK 7:15979

16. Virdee K, Cumming P, Caprioli D et al (2012) Applications of positron emission tomography in animal models of neurological and neuropsychiatric disorders. Neurosci Biobehav Rev 36:1188-1216

17. Karlberg AM, Saether O, Eikenes L, Goa PE (2016) Quantitative comparison of PET performance-Siemens Biograph mCT and mMR. EJNMMI Phys 3(5). https://doi.org/10.1186/s40658-016-0142-7

18. Rausch I, Cal-Gonzalez J, Dapra D et al (2015) Performance evaluation of the Biograph mCT Flow PET/CT system according to the NEMA NU2-2012 standard. EJNMMI Phys 2:26. https://doi.org/ 10.1186/s40658-015-0132-1

19. Goertzen AL, Bao Q, Bergeron $M$ et al (2012) NEMA NU 4-2008 comparison of preclinical PET imaging systems. J Nucl Med 53:1300-1309

20. Nagy K, Toth M, Major P et al (2013) Performance evaluation of the small-animal nanoScan PET/MRI system. J Nucl Med 54:1825-1832

21. Levin CS, Zaidi H (2007) Current trends in preclinical PET system design. PET Clinics 2:125-160 
22. Mannheim JG, Schmid AM, Schwenck J et al (2018) PET/MRI hybrid systems. Semin Nucl Med 48:332-347

23. Badea A, Ali-Sharief AA, Johnson GA (2007) Morphometric analysis of the C57BL/6J mouse brain. Neuroimage 37:683-693

24. Ma Y, Hof PR, Grant SC et al (2005) A three-dimensional digital atlas database of the adult $\mathrm{C} 57 \mathrm{BL} / 6 \mathrm{~J}$ mouse brain by magnetic resonance microscopy. Neuroscience 135:1203-1215

25. Lin YS, Wang HY, Huang DF et al (2016) Neuronal splicing regulator RBFOX3 (NeuN) regulates adult hippocampal neurogenesis and synaptogenesis. PLoS One 11:e0164164

26. Hume SP, Jones T (1998) Positron emission tomography (PET) methodology for small animals and its application in radiopharmaceutical preclinical investigation. Nucl Med Biol 25:729-732

27. Moses WW (2011) Fundamental limits of spatial resolution in PET. Nucl Instrum Methods A 648:S236-S240

28. Kolb A, Parl C, Mantlik F et al (2014) Development of a novel depth of interaction PET detector using highly multiplexed G-APD crossstrip encoding. Med Phys 41:081916

29. Kang HG, Hong SJ, Ko GB et al (2015) Assessment of MRcompatibility of SiPM PET insert using short optical fiber bundles for small animal research. J Instrum 10:P12008-P12008

30. Ko GB, Yoon HS, Kim KY et al (2016) Simultaneous multiparametric PET/MRI with silicon photomultiplier PET and ultra-high-field MRI for small-animal imaging. J Nucl Med 57:1309-1315

31. Olcott P, Kim E, Hong K et al (2015) Prototype positron emission tomography insert with electro-optical signal transmission for simultaneous operation with MRI. Phys Med Biol 60:3459-3478

32. Catana C, Wu Y, Judenhofer MS, Qi J, Pichler BJ, Cherry SR (2006) Simultaneous acquisition of multislice PET and MR images: initial results with a MR-compatible PET scanner. J Nucl Med 47:19681976

33. Maramraju SH, Smith SD, Junnarkar SS et al (2011) Small animal simultaneous PET/MRI: initial experiences in a 9.4 T microMRI. Phys Med Biol 56:2459-2480

34. Wehrl HF, Schwab J, Hasenbach K et al (2013) Multimodal elucidation of choline metabolism in a murine glioma model using magnetic resonance spectroscopy and ${ }^{11} \mathrm{C}$-choline positron emission tomography. Cancer Res 73:1470-1480

35. Weissler B, Gebhardt P, Lerche CW et al (2014) MR compatibility aspects of a silicon photomultiplier-based PET/RF insert with integrated digitisation. Phys Med Biol 59:5119-5139

36. Yamamoto S, Watabe T, Watabe H et al (2012) Simultaneous imaging using Si-PM-based PET and MRI for development of an integrated PET/MRI system. Phys Med Biol 57:N1-N13

37. Yoon HS, Ko GB, Kwon SI et al (2012) Initial results of simultaneous PET/MRI experiments with an MRI-compatible silicon photomultiplier PET scanner. J Nucl Med 53:608-614

38. Hutchins GD, Miller MA, Soon VC, Receveur T (2008) Small animal PET imaging. ILAR J 49:54-65

39. Yao R, Lecomte R, Crawford ES (2012) Small-animal PET: what is it, and why do we need it? J Nucl Med Technol 40:157-165

40. Tong S, Alessio AM, Kinahan PE (2010) Image reconstruction for PET/CT scanners: past achievements and future challenges. Imaging Med 2:529-545

41. Jones T, Rabiner EA, Company PETRA (2012) The development, past achievements, and future directions of brain PET. J Cereb Blood Flow Metab 32:1426-1454

42. Van Heertum RL, Masanori Ichise MDF, Tikofsky RS (2015) Functional cerebral SPECT and PET imaging. Wolters Kluwer Health, Philadelphia

43. Burger C, Deschwanden A, Ametamey S et al (2010) Evaluation of a bolus/infusion protocol for ${ }^{11} \mathrm{C}-\mathrm{ABP} 688$, a PET tracer for mGluR5. Nucl Med Biol 37:845-851

44. Lammertsma AA, Hume SP (1996) Simplified reference tissue model for PET receptor studies. Neuroimage 4:153-158

45. Shi X, Li N, Ding H et al (2018) Comparison among reconstruction algorithms for quantitative analysis of ${ }^{11} \mathrm{C}$-acetate cardiac PET imaging. Contrast Media Mol Imaging 2018:9193403

46. Morimoto T, Ito H, Takano A et al (2006) Effects of image reconstruction algorithm on neurotransmission PET studies in humans: comparison between filtered backprojection and ordered subsets expectation maximization. Ann Nucl Med 20:237-243

47. Vunckx K, Dupont P, Goffin K et al (2014) Voxel-based comparison of state-of-the-art reconstruction algorithms for ${ }^{18} \mathrm{~F}$-FDG PET brain imaging using simulated and clinical data. Neuroimage 102(Pt 2):875-884

48. Thiyagarajan A, Rajasekaran PM, Subramanian K (2014) A quantitative assessment of PET brain image reconstruction using MAP and neural network based segmentation of CG algorithm. Int J Comput Inform Syst Indust Manag Appl 6:381-390

49. Frey EC, Humm JL, Ljungberg M (2012) Accuracy and precision of radioactivity quantification in nuclear medicine images. Semin Nucl Med 42:208-218

50. Dupont P, Warwick J (2009) Kinetic modelling in small animal imaging with PET. Methods 48:98-103

51. Chow PL, Rannou FR, Chatziioannou AF (2005) Attenuation correction for small animal PET tomographs. Phys Med Biol 50:1837-1850

52. El Ali HH, Bodholdt RP, Jorgensen JT, Myschetzky R, Kjaer A (2012) Importance of attenuation correction (AC) for small animal PET imaging. Diagnostics 2:42-51

53. Mannheim JG, Schmid AM, Pichler BJ (2017) Influence of Co-57 and CT transmission measurements on the quantification accuracy and partial volume effect of a small animal PET scanner. Mol Imaging Biol 19:825-836

54. Mannheim JG, Judenhofer MS, Schmid A et al (2012) Quantification accuracy and partial volume effect in dependence of the attenuation correction of a state-of-the-art small animal PET scanner. Phys Med Biol 57:3981-3993

55. Catana C (2015) Motion correction options in PET/MRI. Semin Nucl Med 45:212-223

56. Rahmim A, Rousset O, Zaidi H (2007) Strategies for motion tracking and correction in PET. PET Clinics 2:251-266

57. Catana C, Benner T, van der Kouwe A et al (2011) MRI-assisted PET motion correction for neurologic studies in an integrated MR-PET scanner. J Nucl Med 52:154-161

58. Furst S, Grimm R, Hong I et al (2015) Motion correction strategies for integrated PET/MR. J Nucl Med 56:261-269

59. Wurslin C, Schmidt H, Martirosian P et al (2013) Respiratory motion correction in oncologic PET using T1-weighted MR imaging on a simultaneous whole-body PET/MR system. J Nucl Med 54:464-471

60. Schiffer WK, Mirrione MM, Biegon A, Alexoff DL, Patel V, Dewey SL (2006) Serial microPET measures of the metabolic reaction to a microdialysis probe implant. J Neurosci Methods 155:272-284

61. Mirrione MM, Schiffer WK, Fowler JS, Alexoff DL, Dewey SL, Tsirka SE (2007) A novel approach for imaging brain-behavior relationships in mice reveals unexpected metabolic patterns during seizures in the absence of tissue plasminogen activator. Neuroimage 38:34-42

62. Casteels C, Vermaelen P, Nuyts J et al (2006) Construction and evaluation of multitracer small-animal PET probabilistic atlases for voxel-based functional mapping of the rat brain. J Nucl Med 47:18581866

63. Verhaeghe J, Wyffels L, Wyckhuys $\mathrm{T}$ et al (2014) Rat brain normalization templates for robust regional analysis of $\left[{ }^{11} \mathrm{C}\right] \mathrm{ABP} 688$ positron emission tomography/computed tomography. Mol Imaging 13

64. Vallez Garcia D, Casteels C, Schwarz AJ et al (2015) A standardized method for the construction of tracer specific PET and SPECT rat brain templates: validation and implementation of a toolbox. PLoS One 10:e 0122363

65. Mannheim JG, Wehrl HF, Judenhofer MS, Pichler BJ (2011) Small animal PET cameras - development, technology, PET/CT, PET/MRI. In Trends on the role of PET in drug development. World Sci, pp 289-317

66. Soret M, Bacharach SL, Buvat I (2007) Partial-volume effect in PET tumor imaging. J Nucl Med 48:932-945

67. Hoffman EJ, Huang SC, Phelps ME (1979) Quantitation in positron emission computed tomography: 1. Effect of object size. J Comput Assist Tomogr 3:299-308

68. Muellauer J, Willimayer R, Goertzen $\mathrm{AL}$ et al $(2013){ }^{18} \mathrm{~F},{ }^{11} \mathrm{C}$ and ${ }^{58} \mathrm{Ga}$ in small animal PET imaging. Evaluation of partial volume correction methods. Nuklearmedizin Nuclear Medicine 52:250-261

69. Disselhorst JA, Brom M, Laverman P et al (2010) Image-quality assessment for several positron emitters using the NEMA NU 4-2008 standards in the Siemens Inveon small-animal PET scanner. J Nucl Med 51:610-617

70. Erlandsson K, Buvat I, Pretorius PH et al (2012) A review of partial volume correction techniques for emission tomography and their 
applications in neurology, cardiology and oncology. Phys Med Biol 57:R119-R159

71. Rousset OG, Ma Y, Evans AC (1998) Correction for partial volume effects in PET: principle and validation. J Nucl Med 39:904-911

72. Hume SP, Opacka-Juffry J, Myers R et al (1995) Effect of L-dopa and 6-hydroxydopamine lesioning on $\left[{ }^{11} \mathrm{C}\right]$ raclopride binding in rat striatum, quantified using PET. Synapse 21:45-53

73. Noguchi J, Zhang MR, Yanamoto K, Nakao R, Suzuki K (2008) In vitro binding of $\left[{ }^{11} \mathrm{C}\right]$ raclopride with ultrahigh specific activity in rat brain determined by homogenate assay and autoradiography. Nucl Med Biol 35:19-27

74. Kuwabara H, Chamroonrat W, Mathews W et al (2011) Evaluation of ${ }^{11} \mathrm{C}-\mathrm{ABP} 688$ and ${ }^{18} \mathrm{~F}-\mathrm{FPEB}$ for imaging mGluR5 receptors in the human brain. J Nucl Med 52:390

75. Elmenhorst D, Aliaga A, Bauer A, Rosa-Neto P (2012) Test-retest stability of cerebral mGluR5 quantification using $\left[{ }^{11} \mathrm{C}\right] \mathrm{ABP} 688$ and positron emission tomography in rats. Synapse 66:552-560

76. Sijbesma JWA, van Waarde A, Vállez García D et al (2018) Testretest stability of cerebral 2-deoxy-2-[ $\left.{ }^{18} \mathrm{~F}\right]$ fluoro-D-glucose $\left(\left[{ }^{18} \mathrm{~F}\right] \mathrm{FDG}\right)$ positron emission tomography (PET) in male and female rats. Mol Imaging Biol 21. https://doi.org/10.1007/s11307-018-1245-4

77. Aznavour N, Benkelfat C, Gravel P et al (2008) MicroPET imaging of 5-HT1A receptors in rat brain: a test-retest $\left[{ }^{18} \mathrm{~F}\right] \mathrm{MPPF}$ study. Eur J Nucl Med Mol Imaging 36:53

78. Avendano-Estrada A, Avila-Rodriguez MA (2018) Reference tissue models in the assessment of ${ }^{11} \mathrm{C}$-DTBZ binding to the VMAT2 in rat striatum: a test-retest reproducibility study. Synapse 72:e22029

79. Sijbesma JW, Zhou X, Vallez Garcia D et al (2016) Novel approach to repeated arterial blood sampling in small animal PET: application in a test-retest study with the adenosine A1 receptor ligand $\left[{ }^{11} \mathrm{C}\right] \mathrm{MPDX}$. Mol Imaging Biol 18:715-723

80. Sephton SM, Herde AM, Mu L et al (2015) Preclinical evaluation and test-retest studies of $\left[{ }^{18} \mathrm{~F}\right] \mathrm{PSS} 232$, a novel radioligand for targeting metabotropic glutamate receptor 5 (mGlu5). Eur J Nucl Med Mol Imaging 42:128-137

81. Zhou X, de Vries E, Koole M, Dierckx R, Elsinga P (2015) In vivo evaluation of $\left[{ }^{11} \mathrm{C}\right]$ preladenant for imaging of adenosine $\mathrm{A} 2 \mathrm{~A}$ receptors in rat brain: kinetic modelling and test/retest variability. $\mathrm{J}$ Nucl Med 56:488

82. Alexoff DL, Vaska P, Marsteller D et al (2003) Reproducibility of ${ }^{11} \mathrm{C}$-raclopride binding in the rat brain measured with the microPET R4: effects of scatter correction and tracer specific activity. J Nucl Med 44:815-822

83. Kroll T, Elmenhorst D, Weisshaupt A et al (2014) Reproducibility of non-invasive A1 adenosine receptor quantification in the rat brain using $\left[{ }^{18} \mathrm{~F}\right] \mathrm{CPFPX}$ and positron emission tomography. Mol Imaging Biol 16:699-709

84. Elmenhorst $\mathrm{D}$, Kroll $\mathrm{T}$, Wedekind $\mathrm{F}$ et al (2013) In vivo kinetic and steady-state quantification of ${ }^{18} \mathrm{~F}-\mathrm{CPFPX}$ binding to rat cerebral A1 adenosine receptors: validation by displacement and autoradiographic experiments. J Nucl Med 54:1411-1419

85. van Berckel BN, Ossenkoppele R, Tolboom N et al (2013) Longitudinal amyloid imaging using ${ }^{11} \mathrm{C}-\mathrm{PiB}$ : methodologic considerations. J Nucl Med 54:1570-1576

86. Keyes JW Jr (1995) SUV: standard uptake or silly useless value? J Nucl Med 36:1836-1839

87. Huang SC (2000) Anatomy of SUV. Standardized uptake value. Nucl Med Biol 27:643-646

88. Lammertsma AA (2017) Forward to the past: the case for quantitative PET imaging. J Nucl Med 58:1019-1024

89. Lammertsma AA, Bench CJ, Hume SP et al (1996) Comparison of methods for analysis of clinical $\left[{ }^{11} \mathrm{C}\right]$ raclopride studies. J Cereb Blood Flow Metab 16:42-52

90. Schmidt KC, Turkheimer FE (2002) Kinetic modeling in positron emission tomography. Quart J Nucl Med 46:70-85

91. Gunn RN, Gunn SR, Turkheimer FE et al (2002) Positron emission tomography compartmental models: a basis pursuit strategy for kinetic modeling. J Cereb Blood Flow Metab 22:1425-1439

92. Gunn RN, Gunn SR, Cunningham VJ (2001) Positron emission tomography compartmental models. J Cereb Blood Flow Metab 21:635-652

93. Koeppe RA, Holthoff VA, Frey KA et al (1991) Compartmental analysis of $\left[{ }^{11} \mathrm{C}\right]$ flumazenil kinetics for the estimation of ligand transport rate and receptor distribution using positron emission tomography. J Cereb Blood Flow Metab 11:735-744

94. Innis RB, Cunningham VJ, Delforge $\mathrm{J}$ et al (2007) Consensus nomenclature for in vivo imaging of reversibly binding radioligands. J Cereb Blood Flow Metab 27:1533-1539

95. Weber B, Burger C, Biro P, Buck A (2002) A femoral arteriovenous shunt facilitates arterial whole blood sampling in animals. Eur J Nucl Med Mol Imaging 29:319-323

96. Herfert K, Marciano S, Kuebler L et al (2019) Preclinical experimentation (neurology). In: Lewis JS, Windhorst AD, Zeglis BM (eds) Radiopharmaceutical chemistry. Springer, Berlin

97. Napieczynska H, Kolb A, Katiyar P et al (2018) Impact of the AIF recording method on kinetic parameters in small animal PET. J Nucl Med 59:1159-1164

98. Kimura Y, Seki C, Hashizume N et al (2013) Novel system using microliter order sample volume for measuring arterial radioactivity concentrations in whole blood and plasma for mouse PET dynamic study. Phys Med Biol 58:7889-7903

99. Yee SH, Jerabek PA, Fox PT (2005) Non-invasive quantification of cerebral blood flow for rats by microPET imaging of 150 labelled water: the application of a cardiac time-activity curve for the tracer arterial input function. Nucl Med Commun 26:903-911

100. Fang YH, Muzic RF Jr (2008) Spillover and partial-volume correction for image-derived input functions for small-animal ${ }^{18} \mathrm{~F}-$ FDG PET studies. J Nucl Med 49:606-614

101. Cunningham VJ, Hume SP, Price GR et al (1991) Compartmental analysis of diprenorphine binding to opiate receptors in the rat in vivo and its comparison with equilibrium data in vitro. $\mathrm{J}$ Cereb Blood Flow Metab 11:1-9

102. Finnema SJ, Nabulsi NB, Eid $T$ et al (2016) Imaging synaptic density in the living human brain. Sci Transl Med 8:348ra396

103. Becker G, Warnier C, Serrano ME et al (2017) Pharmacokinetic characterization of $\left[{ }^{18} \mathrm{~F}\right] \mathrm{UCB}-\mathrm{H}$ PET radiopharmaceutical in the rat brain. Mol Pharm 14:2719-2725

104. Lacan G, Plenevaux A, Rubins DJ et al (2008) Cyclosporine, a Pglycoprotein modulator, increases $\left[{ }^{18} \mathrm{~F}\right] \mathrm{MPPF}$ uptake in rat brain and peripheral tissues: microPET and ex vivo studies. Eur J Nucl Med Mol Imaging 35:2256-2266

105. Liow JS, Lu S, McCarron JA et al (2007) Effect of a P-glycoprotein inhibitor, Cyclosporin A, on the disposition in rodent brain and blood of the 5-HT1A receptor radioligand, $\left[{ }^{11} \mathrm{C}\right](\mathrm{R})-(-)-\mathrm{RWAY}$. Synapse 61:96-105

106. Kroll T, Elmenhorst D, Matusch A et al (2014) $\left[{ }^{18}\right.$ F $]$ Altanserin and small animal PET: impact of multidrug efflux transporters on ligand brain uptake and subsequent quantification of 5-HT(2)A receptor densities in the rat brain. Nucl Med Biol 41:1-9

107. Syvanen S, Lindhe O, Palner M et al (2009) Species differences in blood-brain barrier transport of three positron emission tomography radioligands with emphasis on P-glycoprotein transport. Drug Metab Dispos 37:635-643

108. Elsinga PH, Hendrikse NH, Bart J et al (2005) Positron emission tomography studies on binding of central nervous system drugs and P-glycoprotein function in the rodent brain. Mol Imaging Biol 7:3744

109. Tournier N, Cisternino S, Peyronneau MA et al (2012) Discrepancies in the P-glycoprotein-mediated transport of ${ }^{18} \mathrm{~F}-\mathrm{MPPF}$ : a pharmacokinetic study in mice and non-human primates. Pharm Res 29:24682476

110. Kroll T, Elmenhorst D, Matusch A et al (2013) Suitability of $[18 \mathrm{~F}]$ altanserin and PET to determine 5-HT2A receptor availability in the rat brain: in vivo and in vitro validation of invasive and noninvasive kinetic models. Mol Imaging Biol 15:456-467

111. Riss PJ, Hong YT, Williamson D et al (2011) Validation and quantification of $[18 \mathrm{~F}]$ altanserin binding in the rat brain using blood input and reference tissue modeling. J Cereb Blood Flow Metab 31:2334-2342

112. Sadzot B, Lemaire C, Maquet P et al (1995) Serotonin 5HT2 receptor imaging in the human brain using positron emission tomography and a new radioligand, $\left[{ }^{18} \mathrm{~F}\right]$ altanserin: results in young normal controls. J Cereb Blood Flow Metab 15:787-797

113. Skaddan MB, Sherman PS, Kilbourn MR (2001) The role of speciesdependent metabolism in the regional brain retention of $18 \mathrm{~F}$-labeled muscarinic acetylcholine receptor ligands. Nucl Med Biol 28:753759 
114. Walker MD, Dinelle K, Kornelsen R et al (2013) In-vivo measurement of LDOPA uptake, dopamine reserve and turnover in the rat brain using $\left[{ }^{18}\right.$ F]FDOPA PET. J Cereb Blood Flow Metab 33:59-66

115. Pike VW (2009) PET radiotracers: crossing the blood-brain barrier and surviving metabolism. Trends Pharmacol Sci 30:431-440

116. Brown AK, Kimura Y, Zoghbi SS et al (2008) Metabotropic glutamate subtype 5 receptors are quantified in the human brain with a novel radioligand for PET. J Nucl Med 49:2042-2048

117. Shetty HU, Zoghbi SS, Simeon FG et al (2008) Radiodefluorination of 3-fluoro-5-(2-(2-[ $\left.{ }^{18} \mathrm{~F}\right]$ (fluoromethyl)-thiazol-4yl)ethynyl)benzonitrile $\left(\left[{ }^{18} \mathrm{~F}\right] \mathrm{SP} 203\right)$, a radioligand for imaging brain metabotropic glutamate subtype- 5 receptors with positron emission tomography, occurs by glutathionylation in rat brain. J Pharmacol Exp Ther 327:727-735

118. Fischer K (2012) Thesis: Limits and possibilities of the in vivo quantification of the dopaminergic system in rats and mice using positron emission tomography. In Department of Preclinical Imaging and Radiopharmacy. Library: Eberhard-Karls University of Tuebingen, $\mathrm{p} 433$

119. Doudet DJ, Jivan S, Ruth TJ, Holden JE (2002) Density and affinity of the dopamine D2 receptors in aged symptomatic and asymptomatic MPTP-treated monkeys: PET studies with $\left[{ }^{11} \mathrm{C}\right]$ raclopride. Synapse 44:198-202

120. Holden JE, Jivan S, Ruth TJ, Doudet DJ (2002) In vivo receptor assay with multiple ligand concentrations: an equilibrium approach. J Cereb Blood Flow Metab 22:1132-1141

121. Ikoma Y, Watabe H, Hayashi T et al (2009) Quantitative evaluation of changes in binding potential with a simplified reference tissue model and multiple injections of $\left[{ }^{11} \mathrm{C}\right]$ raclopride. Neuroimage 47:1639-1648

122. Ikoma $Y$, Watabe H, Hayashi $T$ et al (2010) Measurement of density and affinity for dopamine $\mathrm{D}_{2}$ receptors by a single positron emission tomography scan with multiple injections of $\left[{ }^{11} \mathrm{C}\right]$ raclopride. $\mathrm{J}$ CerebBlood Flow Metab 30:663-673

123. Delforge J, Spelle L, Bendriem B et al (1996) Quantitation of benzodiazepine receptors in human brain using the partial saturation method. J Nucl Med 37:5-11

124. Leriche L, Bjorklund T, Breysse $\mathrm{N}$ et al (2009) Positron emission tomography imaging demonstrates correlation between behavioral recovery and correction of dopamine neurotransmission after gene therapy. J Neurosci 29:1544-1553

125. Wimberley CJ, Fischer K, Reilhac A et al (2014) A data driven method for estimation of $\mathrm{B}$ (avail) and appK(D) using a single injection protocol with $\left[{ }^{11} \mathrm{C}\right]$ raclopride in the mouse. Neuroimage 99:365-376

126. Wimberley C, Angelis G, Boisson F et al (2014) Simulation-based optimisation of the PET data processing for partial saturation approach protocols. Neuroimage 97:29-40

127. Laruelle M (2000) Imaging synaptic neurotransmission with in vivo binding competition techniques: a critical review. J Cereb Blood Flow Metab 20:423-451

128. Paterson LM, Tyacke RJ, Nutt DJ, Knudsen GM (2010) Measuring endogenous 5-HT release by emission tomography: promises and pitfalls. J Cereb Blood Flow 30:1682-1706

129. Sahin G, Thompson LH, Lavisse S et al (2014) Differential dopamine receptor occupancy underlies L-DOPA-induced dyskinesia in a rat model of Parkinson's disease. PLoS One 9:e90759

130. Houston GC, Hume SP, Hirani E et al (2004) Temporal characterisation of amphetamine-induced dopamine release assessed with $\left[{ }^{11} \mathrm{C}\right]$ raclopride in anaesthetised rodents. Synapse 51:206-212

131. Hume SP, Myers R, Bloomfield PM et al (1992) Quantitation of carbon-11-labeled raclopride in rat striatum using positron emission tomography. Synapse 12:47-54

132. Kuczenski R, Segal DS (1999) Dynamic changes in sensitivity occur during the acute response to cocaine and methylphenidate. Psychopharmacol (Berl) 147:96-103

133. Laruelle M, Iyer RN, al-Tikriti MS et al (1997) Microdialysis and SPECT measurements of amphetamine-induced dopamine release in nonhuman primates. Synapse 25:1-14

134. Skinbjerg M, Liow JS, Seneca N et al (2010) D2 dopamine receptor internalization prolongs the decrease of radioligand binding after amphetamine: a PET study in a receptor internalization-deficient mouse model. Neuroimage 50:1402-1407
135. Hwang DR, Kegeles LS, Laruelle M (2000) (-)-N-[(11)C]propylnorapomorphine: a positron-labeled dopamine agonist for PET imaging of $\mathrm{D}_{2}$ receptors. Nucl Med Biol 27:533-539

136. Wilson AA, McCormick P, Kapur S et al (2005) Radiosynthesis and evaluation of $\left[{ }^{11} \mathrm{C}\right]-(+)-4$-propyl-3,4,4a,5,6,10b-hexahydro-2Hnaphtho[1,2-b][1,4]oxazin-9-ol as a potential radiotracer for in vivo imaging of the dopamine D2 high-affinity state with positron emission tomography. J Med Chem 48:4153-4160

137. Finnema SJ, Seneca N, Farde L et al (2005) A preliminary PET evaluation of the new dopamine D2 receptor agonist $\left[{ }^{11} \mathrm{C}\right] \mathrm{MNPA}$ in cynomolgus monkey. Nucl Med Biol 32:353-360

138. Seneca N, Zoghbi SS, Skinbjerg M et al (2008) Occupancy of dopamine $\mathrm{D} 2 / 3$ receptors in rat brain by endogenous dopamine measured with the agonist positron emission tomography radioligand $\left[{ }^{11} \mathrm{C}\right]$ MNPA. Synapse 62:756-763

139. Galineau L, Wilson AA, Garcia A et al (2006) In vivo characterization of the pharmacokinetics and pharmacological properties of $\left[{ }^{11} \mathrm{C}\right]-(+)-\mathrm{PHNO}$ in rats using an intracerebral beta-sensitive system. Synapse 60:172-183

140. Narendran R, Mason NS, Laymon CM et al (2010) A comparative evaluation of the dopamine $\mathrm{D}(2 / 3)$ agonist radiotracer $\left[{ }^{11} \mathrm{C}\right](-)-\mathrm{N}-$ propyl-norapomorphine and antagonist [11C]raclopride to measure amphetamine-induced dopamine release in the human striatum. J Pharmacol Exp Therap 333:533-539

141. Jørgensen LM, Weikop P, Villadsen J et al (2016) Cerebral 5-HT release correlates with $\left[{ }^{11} \mathrm{C}\right] \mathrm{Cimbi} 36$ PET measures of 5-HT2A receptor occupancy in the pig brain. J Cereb Blood Flow Metab $37: 425-434$

142. Jørgensen LM, Weikop P, Svarer C et al (2017) Cerebral serotonin release correlates with $\left[{ }^{11} \mathrm{C}\right] \mathrm{AZ10419369}$ PET measures of 5-HT 1B receptor binding in the pig brain. J Cereb Blood Flow Metab 38:1243-1252

143. Jorgensen LM, Weikop P, Svarer C et al (2017) Cerebral serotonin release correlates with $\left[{ }^{11} \mathrm{C}\right] \mathrm{AZ} 10419369$ PET measures of 5-HT1B receptor binding in the pig brain. J Cereb Blood Flow Metab 38:1243-1252

144. Landau AM, Doudet DJ, Jakobsen S (2012) Amphetamine challenge decreases yohimbine binding to $\alpha 2$ adrenoceptors in Landrace pig brain. Psychopharmacol 222:155-163

145. Finnema SJ, Hughes ZA, Haaparanta-Solin M et al (2014) Amphetamine decreases alpha2C-adrenoceptor binding of $\left[{ }^{11} \mathrm{C}\right]$ ORM-13070: a PET study in the primate brain. Int $\mathrm{J}$ Neuropsychopharmacol 18. https://doi.org/10.1093/ijnp/pyu081

146. Phan JA, Landau AM, Wong DF et al (2015) Quantification of $\left[{ }^{11} \mathrm{C}\right]$ yohimbine binding to alpha 2 adrenoceptors in rat brain in vivo. J Cereb Blood Flow Metab 35:501-511

147. Idzko M, Ferrari D, Eltzschig HK (2014) Nucleotide signalling during inflammation. Nature 509:310-317

148. Sperlagh B, Vizi ES (2011) The role of extracellular adenosine in chemical neurotransmission in the hippocampus and basal ganglia: pharmacological and clinical aspects. Curr Top Med Chem 11:1034 1046

149. Noguchi J, Ishiwata K, Furuta R et al (1997) Evaluation of carbon-11 labeled KF15372 and its ethyl and methyl derivatives as a potential CNS adenosine A1 receptor ligand. Nucl Med Biol 24:53-59

150. Holschbach MH, Olsson RA, Bier D et al (2002) Synthesis and evaluation of no-carrier-added 8-cyclopentyl-3-(3$\left[{ }^{18} \mathrm{~F}\right]$ fluoropropyl)-1-propylxanthine $\left(\left[{ }^{18} \mathrm{~F}\right] \mathrm{CPFPX}\right)$ : a potent and selective A1-adenosine receptor antagonist for in vivo imaging. $\mathrm{J}$ Med Chem 45:5150-5156

151. Zhou X, Khanapur S, de Jong JR et al (2017) In vivo evaluation of $\left[{ }^{11} \mathrm{C}\right]$ preladenant positron emission tomography for quantification of adenosine A2A receptors in the rat brain. J Cereb Blood Flow Metab 37:577-589

152. Ishiwata K, Wang WF, Kimura $Y$ et al (2003) Preclinical studies on $\left[{ }^{11} \mathrm{C}\right]$ TMSX for mapping adenosine A2A receptors by positron emission tomography. Ann Nucl Med 17:205-211

153. Moresco RM, Todde S, Belloli S et al (2005) In vivo imaging of adenosine $\mathrm{A} 2 \mathrm{~A}$ receptors in rat and primate brain using $\left[{ }^{11} \mathrm{C}\right] \mathrm{SCH} 442416$. Eur J Nucl Med Mol Imaging 32:405-413

154. Elmenhorst D, Garibotto V, Prescher A, Bauer A (2011) Adenosine $\mathrm{A}(1)$ receptors in human brain and transfected $\mathrm{CHO}$ cells: inhibition of $\left[{ }^{3} \mathrm{H}\right] \mathrm{CPFPX}$ binding by adenosine and caffeine. Neurosci Lett $487: 415-420$ 
155. Guo M, Gao ZG, Tyler R et al (2018) Preclinical evaluation of the first adenosine A1 receptor partial agonist Radioligand for positron emission tomography imaging. J Med Chem 61:9966-9975

156. Mead BP, Kim N, Miller GW et al (2017) Novel focused ultrasound gene therapy approach noninvasively restores dopaminergic neuron function in a rat Parkinson's disease model. Nano Lett 17:3533-3542

157. Hua Y, Sahashi K, Rigo F et al (2011) Peripheral SMN restoration is essential for long-term rescue of a severe spinal muscular atrophy mouse model. Nature 478:123-126

158. Tomiyama T, Matsuyama S, Iso H et al (2010) A mouse model of amyloid beta oligomers: their contribution to synaptic alteration, abnormal tau phosphorylation, glial activation, and neuronal loss in vivo. J Neurosci 30:4845-4856

159. Boronat-Garcia A, Palomero-Rivero M, Guerra-Crespo $M$ et al (2016) Intrastriatal grafting of chromospheres: survival and functional effects in the 6-OHDA rat model of Parkinson's disease. PLoS One 11:e0160854

160. Chow RD, Guzman CD, Wang G et al (2017) AAV-mediated direct in vivo CRISPR screen identifies functional suppressors in glioblastoma. Nat Neurosci 20:1329-1341

161. Platt RJ, Chen S, Zhou Y et al (2014) CRISPR-Cas9 knockin mice for genome editing and cancer modeling. Cell 159:440-455

162. Lin $\mathrm{H}, \mathrm{Hu} \mathrm{H}$, Duan $\mathrm{W}$ et al (2016) Intramuscular delivery of scAAV9-hIGF1 prolongs survival in the hSOD1(G93A) ALS mouse model via upregulation of D-amino acid oxidase. Mol Neurobiol

163. de Solis CA, Ho A, Holehonnur R, Ploski JE (2016) The development of a viral mediated CRISPR/Cas9 system with doxycycline dependent gRNA expression for inducible in vitro and in vivo genome editing. Front Mol Neurosci 9:70

164. Suzuki K, Tsunekawa Y, Hernandez-Benitez R et al (2016) In vivo genome editing via CRISPR/Cas9 mediated homology-independent targeted integration. Nature 540:144-149

165. Nishiyama J, Mikuni T, Yasuda R (2017) Virus-mediated genome editing via homology-directed repair in mitotic and postmitotic cells in mammalian brain. Neuron 96:755-768 e755

166. Swiech L, Heidenreich M, Banerjee A et al (2015) In vivo interrogation of gene function in the mammalian brain using CRISPR-Cas9. Nat Biotechnol 33:102-106

167. Back S, Necarsulmer J, Whitaker LR et al (2019) Neuron-specific genome modification in the adult rat brain using CRISPR-Cas9 transgenic rats. Neuron 102:105-119

168. Monteys AM, Ebanks SA, Keiser MS, Davidson BL (2017) CRISPR/Cas9 editing of the mutant huntingtin allele in vitro and in vivo. Mol Ther 25:12-23

169. Whitworth KM, Lee K, Benne JA et al (2014) Use of the CRISPR/ Cas9 system to produce genetically engineered pigs from in vitroderived oocytes and embryos. Biol Reprod 91:1-13

170. Zhou X, Xin J, Fan N et al (2015) Generation of CRISPR/Cas9mediated gene-targeted pigs via somatic cell nuclear transfer. Cell Mol Life Sci 72:1175-1184

171. Niu Y, Shen B, Cui Y et al (2014) Generation of gene-modified cynomolgus monkey via Cas9/RNA-mediated gene targeting in onecell embryos. Cell 156:836-843

172. Ohmura Y, Tanaka KF, Tsunematsu T et al (2014) Optogenetic activation of serotonergic neurons enhances anxiety-like behaviour in mice. Int J Neuropsychopharmacol 17:1777-1783

173. Bock R, Shin JH, Kaplan AR et al (2013) Strengthening the accumbal indirect pathway promotes resilience to compulsive cocaine use. Nat Neurosci 16:632-638

174. Krashes MJ, Shah BP, Koda S, Lowell BB (2013) Rapid versus delayed stimulation of feeding by the endogenously released AgRP neuron mediators GABA, NPY, and AgRP. Cell Metab 18:588-595

175. Cai H, Haubensak W, Anthony TE, Anderson DJ (2014) Central amygdala PKC-delta $(+)$ neurons mediate the influence of multiple anorexigenic signals. Nat Neurosci 17:1240-1248

176. Atasoy D, Betley JN, Su HH, Sternson SM (2012) Deconstruction of a neural circuit for hunger. Nature 488:172-177

177. Gomez JL, Bonaventura J, Lesniak W et al (2017) Chemogenetics revealed: DREADD occupancy and activation via converted clozapine. Science 357:503-507

178. Manvich DF, Webster KA, Foster SL et al (2018) The DREADD agonist clozapine N-oxide (CNO) is reverse-metabolized to clozapine and produces clozapine-like interoceptive stimulus effects in rats and mice. Sci Rep-UK 8:3840
179. Mahler SV, Vazey EM, Beckley JT et al (2014) Designer receptors show role for ventral pallidum input to ventral tegmental area in cocaine seeking. Nat Neurosci 17:577-585

180. Thompson KJ, Khajehali E, Bradley SJ et al (2018) DREADD agonist 21 is an effective agonist for muscarinic-based DREADDs in vitro and in vivo. ACS Pharmacol Trans Sci 1:61-72

181. Yuan P, Grutzendler J (2016) Attenuation of beta-amyloid deposition and neurotoxicity by chemogenetic modulation of neural activity. J Neurosci 36:632-641

182. Alcacer C, Andreoli L, Sebastianutto I et al (2017) Chemogenetic stimulation of striatal projection neurons modulates responses to Parkinson's disease therapy. J Clin Invest 127:720-734

183. Chen Y, Xiong M, Dong Y et al (2016) Chemical control of grafted human PSC-derived neurons in a mouse model of Parkinson's disease. Cell Stem Cell 18:817-826

184. Aldrin-Kirk P, Heuer A, Wang G et al (2016) DREADD modulation of transplanted DA neurons reveals a novel parkinsonian dyskinesia mechanism mediated by the serotonin 5-HT6 receptor. Neuron 90:955-968

185. Michaelides M, Hurd YL (2015) DREAMM: a biobehavioral imaging methodology for dynamic in vivo whole-brain mapping of cell type-specific functional networks. Neuropsychopharmacol 40:239-240

186. Michaelides M, Anderson SA, Ananth M et al (2013) Whole-brain circuit dissection in free-moving animals reveals cell-specific mesocorticolimbic networks. J Clin Invest 123:5342-5350

187. Heneka MT, Ramanathan M, Jacobs AH et al (2006) Locus ceruleus degeneration promotes Alzheimer pathogenesis in amyloid precursor protein 23 transgenic mice. J Neurosci 26:1343-1354

188. Thanos PK, Taintor NB, Alexoff D et al (2002) In vivo comparative imaging of dopamine D2 knockout and wild-type mice with ${ }^{11} \mathrm{C}$ raclopride and microPET. J Nucl Med 43:1570-1577

189. Brendel M, Jaworska A, Probst F et al (2016) Small-animal PET imaging of tau pathology with ${ }^{18} \mathrm{~F}$-THK5117 in 2 transgenic mouse models. J Nucl Med 57:792-798

190. Manook A, Yousefi BH, Willuweit A et al (2012) Small-animal PET imaging of amyloid-beta plaques with $\left[{ }^{11} \mathrm{C}\right] \mathrm{PiB}$ and its multi-modal validation in an APP/PS1 mouse model of Alzheimer's disease. PLoS One 7:e31310

191. Brendel M, Jaworska A, Griessinger E et al (2015) Cross-sectional comparison of small animal $\left[{ }^{18} \mathrm{~F}\right]$-florbetaben amyloid-PET between transgenic AD mouse models. PLoS One 10:e116678

192. Maier FC, Wehrl HF, Schmid AM et al (2014) Longitudinal PETMRI reveals beta-amyloid deposition and rCBF dynamics and connects vascular amyloidosis to quantitative loss of perfusion. Nat Med 20:1485-1492

193. Ghaemi M, Hilker R, Rudolf J et al (2002) Differentiating multiple system atrophy from Parkinson's disease: contribution of striatal and midbrain MRI volumetry and multi-tracer PET imaging. J Neurol Neurosurg Psychiatry 73:517-523

194. Segovia F, Illan IA, Gorriz JM et al (2015) Distinguishing Parkinson's disease from atypical parkinsonian syndromes using PET data and a computer system based on support vector machines and Bayesian networks. Front Comput Neurosci 9:137

195. Strome EM, Cepeda IL, Sossi V, Doudet DJ (2006) Evaluation of the integrity of the dopamine system in a rodent model of Parkinson's disease: small animal positron emission tomography compared to behavioral assessment and autoradiography. Mol Imaging Biol 8:292-299

196. Nikolaus S, Larisch R, Beu M et al (2003) Bilateral increase in striatal dopamine D2 receptor density in the 6-hydroxydopaminelesioned rat: a serial in vivo investigation with small animal PET. Eur J Nucl Med Mol Imaging 30:390-395

197. Sharma SK, Ebadi M (2005) Distribution kinetics of 18F-DOPA in weaver mutant mice. Mol Brain Res 139:23-30

198. Antonini A, Leenders KL, Spiegel R et al (1996) Striatal glucose metabolism and dopamine D2 receptor binding in asymptomatic gene carriers and patients with Huntington's disease. Brain 119:2085-2095

199. Feigin A, Leenders KL, Moeller JR et al (2001) Metabolic network abnormalities in early Huntington's disease: an $\left[{ }^{18} \mathrm{~F}\right] \mathrm{FDG}$ PET study. J Nucl Med 42:1591-1595

200. Araujo DM, Cherry SR, Tatsukawa KJ et al (2000) Deficits in striatal dopamine $\mathrm{D}(2)$ receptors and energy metabolism detected by in vivo 
microPET imaging in a rat model of Huntington's disease. Exp Neurol 166:287-297

201. Kaneko G, Sanganahalli BG, Groman SM et al (2017) Hypofrontality and posterior hyperactivity in early schizophrenia: imaging and behavior in a preclinical model. Biol Psychiatry 81:503-513

202. Goff DC, Coyle JT (2001) The emerging role of glutamate in the pathophysiology and treatment of schizophrenia. Am J Psychiatry 158:1367-1377

203. Lin LF, Doherty DH, Lile JD et al (1993) GDNF: a glial cell linederived neurotrophic factor for midbrain dopaminergic neurons. Science 260:1130-1132

204. Sullivan AM, Opacka-Juffry J, Blunt SB (1998) Long-term protection of the rat nigrostriatal dopaminergic system by glial cell linederived neurotrophic factor against 6-hydroxydopamine in vivo. Eur J Neurosci 10:57-63

205. Vandeputte C, Evens N, Toelen J et al (2011) A PET brain reporter gene system based on type 2 cannabinoid receptors. J Nucl Med 52:1102-1109

206. MacLaren DC, Gambhir SS, Satyamurthy N et al (1999) Repetitive, non-invasive imaging of the dopamine $\mathrm{D} 2$ receptor as a reporter gene in living animals. Gene Ther 6:785-791

207. Liang Q, Satyamurthy N, Barrio JR et al (2001) Noninvasive, quantitative imaging in living animals of a mutant dopamine D2 receptor reporter gene in which ligand binding is uncoupled from signal transduction. Gene Ther 8:1490-1498

208. Sellmyer MA, Lee I, Hou C et al (2017) Quantitative PET reporter gene imaging with [(11)C]trimethoprim. Mol Ther 25:120-126

209. Shao Y, Cherry SR, Farahani K et al (1997) Simultaneous PET and MR imaging. Phys Med Biol 42:1965-1970

210. Hammer BE, Christensen NL, Heil BG (1994) Use of a magnetic field to increase the spatial resolution of positron emission tomography. Med Phys 21:1917-1920

211. Pichler BJ, Lorenz E, Mirzoyan R, et al. (1997) Performance test of a LSO-APD PET module in a 9.4 Tesla magnet. In IEEE IEEE, pp $1237-1239$

212. Catana C, Procissi D, Wu Y et al (2008) Simultaneous in vivo positron emission tomography and magnetic resonance imaging. Proc Natl Acad Sci U S A 105:3705-3710

213. Judenhofer MS, Wehrl HF, Newport DF et al (2008) Simultaneous PET-MRI: a new approach for functional and morphological imaging. Nat Med 14:459-465

214. Wehrl HF, Hossain M, Lankes K et al (2013) Simultaneous PETMRI reveals brain function in activated and resting state on metabolic, hemodynamic and multiple temporal scales. Nat Med 19:1184-1189

215. Wehrl HF, Wiehr S, Divine MR et al (2014) Preclinical and translational PET/MR imaging. J Nucl Med 55:11s-18s

216. Wehrl HF, Judenhofer MS, Wiehr S, Pichler BJ (2009) Pre-clinical PET/MR: technological advances and new perspectives in biomedical research. Eur J Nucl Med Mol Imaging 36(Suppl 1):S56-S68

217. Sander CY, Hooker JM, Catana C et al (2013) Neurovascular coupling to D2/D3 dopamine receptor occupancy using simultaneous PET/functional MRI. Proc Natl Acad Sci U S A 110:11169-11174

218. Drzezga A, Arnold S, Minoshima S et al (1999) ${ }^{18}$ F-FDG PET studies in patients with extratemporal and temporal epilepsy: evaluation of an observer-independent analysis. J Nucl Med 40:737-746

219. Sabri O, Hellwig D, Schreckenberger M et al (1998) Correlation of neuropsychological, morphological and functional (regional cerebral blood flow and glucose utilization) findings in cerebral microangiopathy. J Nucl Med 39:147-154

220. Ito S, Kato K, Ikeda M et al (2007) Comparison of ${ }^{18}$ F-FDG PET and bone scintigraphy in detection of bone metastases of thyroid cancer. J Nucl Med 48:889-895

221. Rominger A, Brendel M, Burgold S et al (2013) Longitudinal assessment of cerebral $\beta$-amyloid deposition in mice overexpressing Swedish mutant $\beta$-amyloid precursor protein using ${ }^{18} \mathrm{~F}$-florbetaben PET. J Nucl Med 54:1127-1134

222. Liu Y, Zhu L, Plössl K et al (2010) Optimization of automated radiosynthesis of $[18 \mathrm{~F}] \mathrm{AV}-45$ : a new PET imaging agent for Alzheimer's disease. Nucl Med Biol 37:917-925

223. Snellman A, Rokka J, Lopez-Picon FR et al (2012) Pharmacokinetics of $\left[{ }^{18} \mathrm{~F}\right]$ flutemetamol in wild-type rodents and its binding to beta amyloid deposits in a mouse model of Alzheimer's disease. Eur J Nucl Med Mol Imaging 39:1784-1795

224. Hostetler ED, Walji AM, Zeng Z et al (2016) Preclinical characterization of ${ }^{18} \mathrm{~F}-\mathrm{MK}-6240$, a promising PET tracer for in vivo quantification of human neurofibrillary tangles. J Nucl Med 57:1599-1606

225. Lohith T, Bennacef I, Sur C et al (2017) Quantification of $\left[{ }^{18} \mathrm{~F}\right] \mathrm{MK}$ 6240 , a new PET tracer targeting human neurofibrillary tangles (NFTs) in brain of healthy elderly and subjects with Alzheimer's disease. J Nucl Med 58:277-277

226. W-d H, Herholz K (2006) Brain receptor imaging. J Nucl Med 47:302-312

227. Nagano-Saito A, Lissemore JI, Gravel P, Leyton M, Carbonell F, Benkelfat C (2017) Posterior dopamine D2/3 receptors and brain network functional connectivity. Synapse e21993

228. Constantinescu CC, Coleman RA, Pan ML, Mukherjee J (2011) Striatal and extrastriatal microPET imaging of D2/D3 dopamine receptors in rat brain with $\left[{ }^{18}\right.$ F]fallypride and $\left[{ }^{18} \mathrm{~F}\right]$ desmethoxyfallypride. Synapse 65:778-787

229. Mukherjee J, Constantinescu CC, Hoang AT et al (2015) Dopamine D3 receptor binding of (18)F-fallypride: evaluation using in vitro and in vivo PET imaging studies. Synapse 69:577-591

230. Kornum BR, Lind NM, Gillings N, Marner L, Andersen F, Knudsen GM (2009) Evaluation of the novel 5-HT4 receptor PET ligand $\left[{ }^{11} \mathrm{C}\right] \mathrm{SB} 207145$ in the Gottingen minipig. J Cereb Blood Flow Metab 29:186-196

231. da Cunha-Bang S, Mc Mahon B, MacDonald Fisher P et al (2016) High trait aggression in men is associated with low 5-HT levels, as indexed by 5 -HT 4 receptor binding. Soc Cogn Affect Neurosci 11:548-555

232. Yang KC, Takano A, Halldin C, wr L (2018) Serotonin concentration enhancers at clinically relevant doses reduce $\left[{ }^{1}{ }^{\circ} \mathrm{C}\right] \mathrm{AZ} 10419369$ binding to the 5-HT1B receptors in the nonhuman primate brain. Transl Psychiatry 8:132

233. Deen M, Hansen HD, Hougaard A et al (2017) Low 5-HT 1B receptor binding in the migraine brain: a PET study. Cephalalgia 0:033310241769870

234. Ishibashi K, Miura Y, Ishikawa K et al (2016) Relationship between type 1 metabotropic glutamate receptors and cerebellar ataxia. J Neurol 263:2179-2187

235. Li S, Cai Z, M-q Z et al (2017) A novel ${ }^{18}$ F-labeled kappa opioid receptor antagonist as PET radiotracer: synthesis and in vivo evaluation of ${ }^{18} \mathrm{~F}$-LY2459989 in non-human primates. J Nucl Med 117:140-146

236. Hillmer AT, Holden D, Fowles K et al (2017) Microglial depletion and activation: a [11C]PBR28 PET study in nonhuman primates. EJNMMI Res 7:59

237. Dani M, Wood M, Mizoguchi R et al (2018) Microglial activation correlates in vivo with both tau and amyloid in Alzheimer's disease. Brain 141:2740-2754

238. Datta G, Colasanti A, Rabiner EA et al (2017) Neuroinflammation and its relationship to changes in brain volume and white matter lesions in multiple sclerosis. Brain 140:2927-2938

239. Slupe AM, Kirsch JR (2018) Effects of anesthesia on cerebral blood flow, metabolism, and neuroprotection. J Cereb Blood Flow Metab 38:2192-2208

240. Arakawa R, Farde L, Matsumoto J et al (2018) Potential effect of prolonged sevoflurane anesthesia on the kinetics of $\left[{ }^{11} \mathrm{C}\right]$ raclopride in non-human primates. Mol Imaging Biol 20:183-187

241. Hassoun W, Le Cavorsin M, Ginovart N et al (2003) PET study of the $\left[{ }^{18} \mathrm{C}\right]$ raclopride binding in the striatum of the awake cat: effects of anaesthetics and role of cerebral blood flow. Eur J Nucl Med Mol Imaging 30:141-148

242. Chen Z, Tang J, Liu C et al (2016) Effects of anesthetics on vesicular monoamine transporter type 2 binding to ${ }^{18} \mathrm{~F}-\mathrm{FP}-(+)-\mathrm{DTBZ}$ : a biodistribution study in rat brain. Nucl Med Biol 43:124-129

243. Takuwa H, Maeda J, Ikoma $Y$ et al $(2015)\left[{ }^{18} \mathrm{C}\right]$ Raclopride binding in the striatum of minimally restrained and free-walking awake mice in a positron emission tomography study. Synapse 69:600-606

244. Miranda A, Staelens S, Stroobants S, Verhaeghe J (2017) Fast and accurate rat head motion tracking with point sources for awake brain PET. IEEE Trans Med Imaging 36:1573-1582 
245. Miranda A, Glorie D, Bertoglio D et al (2018) Awake ${ }^{18}$ F-FDG PET imaging of memantine-induced brain activation and test-retest in freely running mice. J Nucl Med 15

246. Kyme AZ, Angelis GI, Eisenhuth J et al (2018) Open-field PET: simultaneous brain functional imaging and behavioural response measurements in freely moving small animals. Neuroimage 188:92101

247. Egerton A, Modinos G, Ferrera D, McGuire P (2017) Neuroimaging studies of GABA in schizophrenia: a systematic review with metaanalysis. Transl Psychiatry 7:e1147

248. Mannheim JG, Kara F, Doorduin J et al (2017) Standardization of small animal imaging - current status and future prospects. Mol Imaging Biol 20:716-731
249. Wu T, Grandjean J, Bosshard SC et al (2017) Altered regional connectivity reflecting effects of different anaesthesia protocols in the mouse brain. Neuroimage 149:190-199

250. Vanhoutte G, Verhoye M, Van der Linden A (2006) Changing body temperature affects the $\mathrm{T} 2 *$ signal in the rat brain and reveals hypothalamic activity. Magn Reson Med 55:1006-1012

251. Gillam JE, Angelis GI, Kyme AZ, Meikle SR (2017) Motion compensation using origin ensembles in awake small animal positron emission tomography. Phys Med Biol 62:715-733

252. Kyme AZ, Zhou VW, Meikle SR et al (2011) Optimised motion tracking for positron emission tomography studies of brain function in awake rats. PLoS One 6:e21727

Publisher's Note. Springer Nature remains neutral with regard to jurisdictional claims in published maps and institutional affiliations. 